\title{
An Introduction to Using Surface Geophysics to Characterize Sand and Gravel Deposits
}

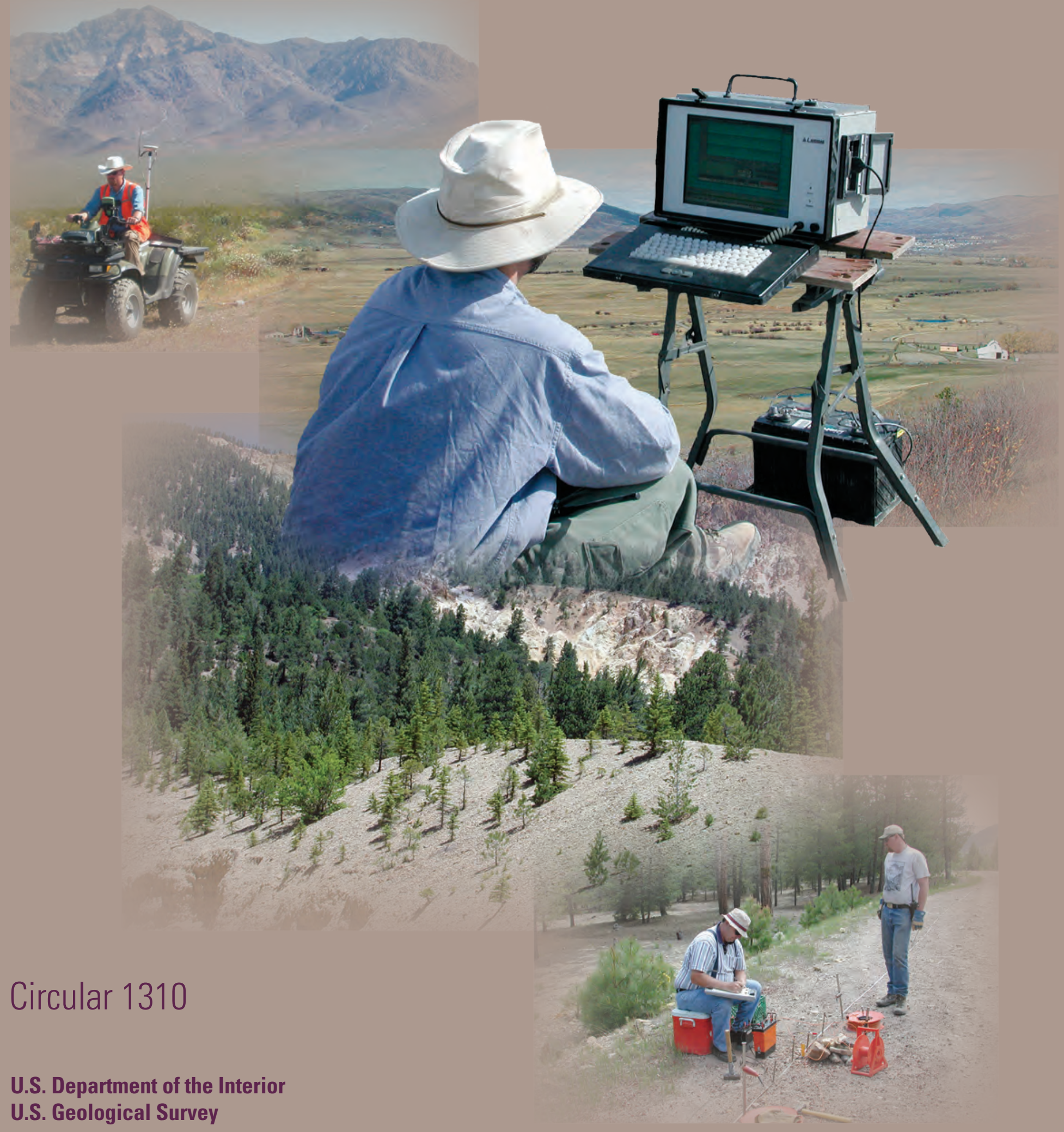



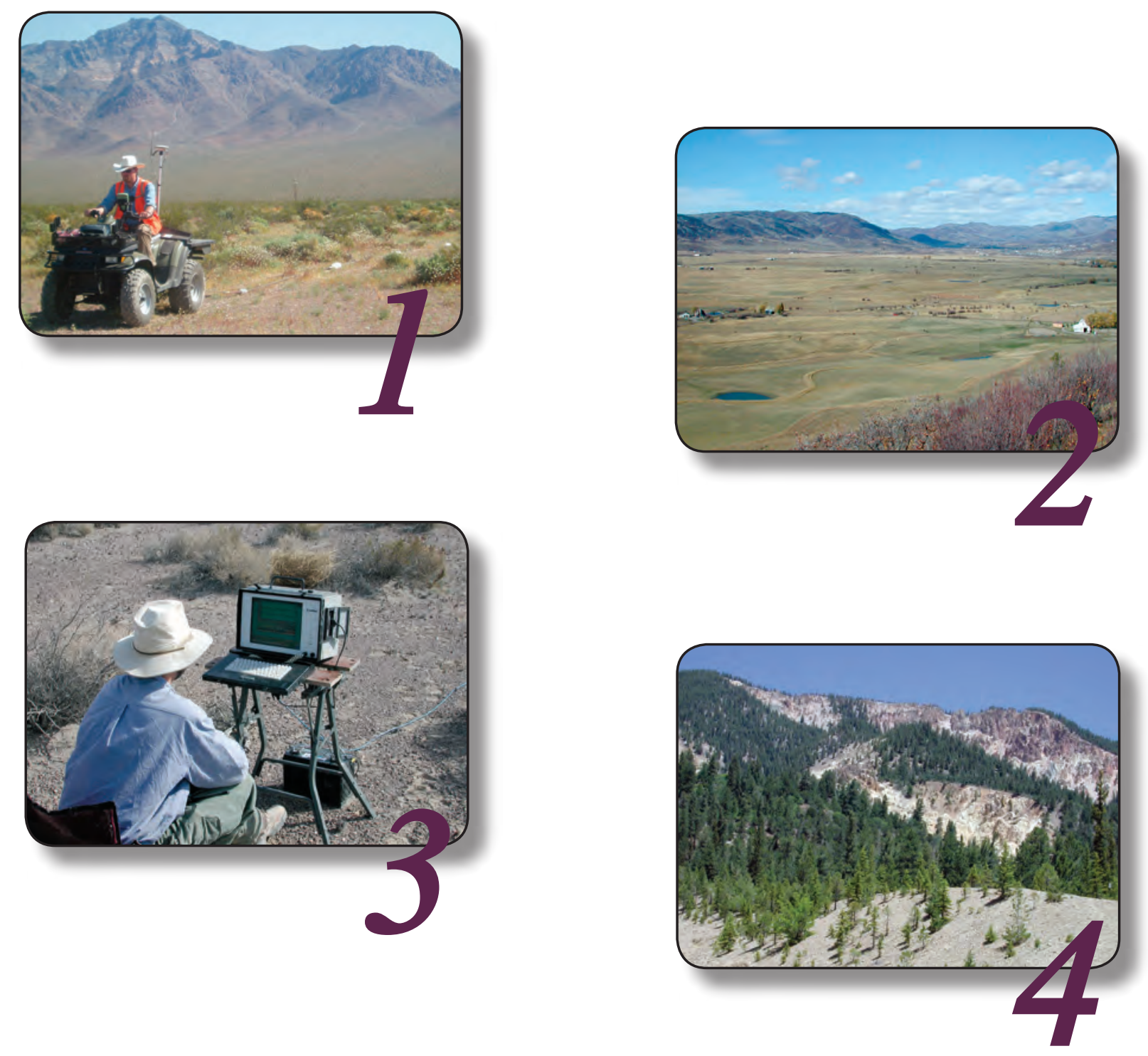

\section{Cover Photographs}

1 Collecting capacitively coupled resistivity data on alluvium in Nevada.

2 View is looking north across a valley south of 2 Steamboat Springs, Colorado.

3 Monitoring seismic data collected on alluvium 3 in Nevada.

4 Gravel deposits near Red River, New Mexico.

5 A four-electrode resistivity survey near Red River, 5 New Mexico

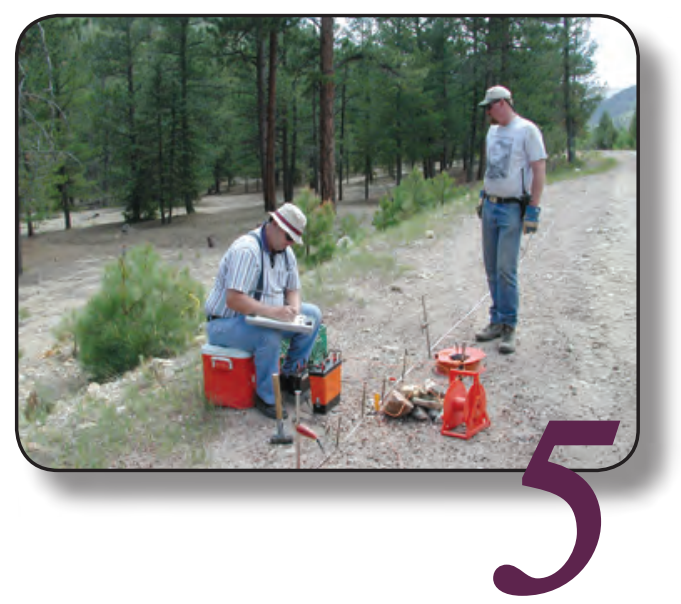




\section{An Introduction to Using Surface Geophysics to Characterize Sand and Gravel Deposits}

By Jeffrey E. Lucius, William H. Langer, and Karl J. Ellefsen

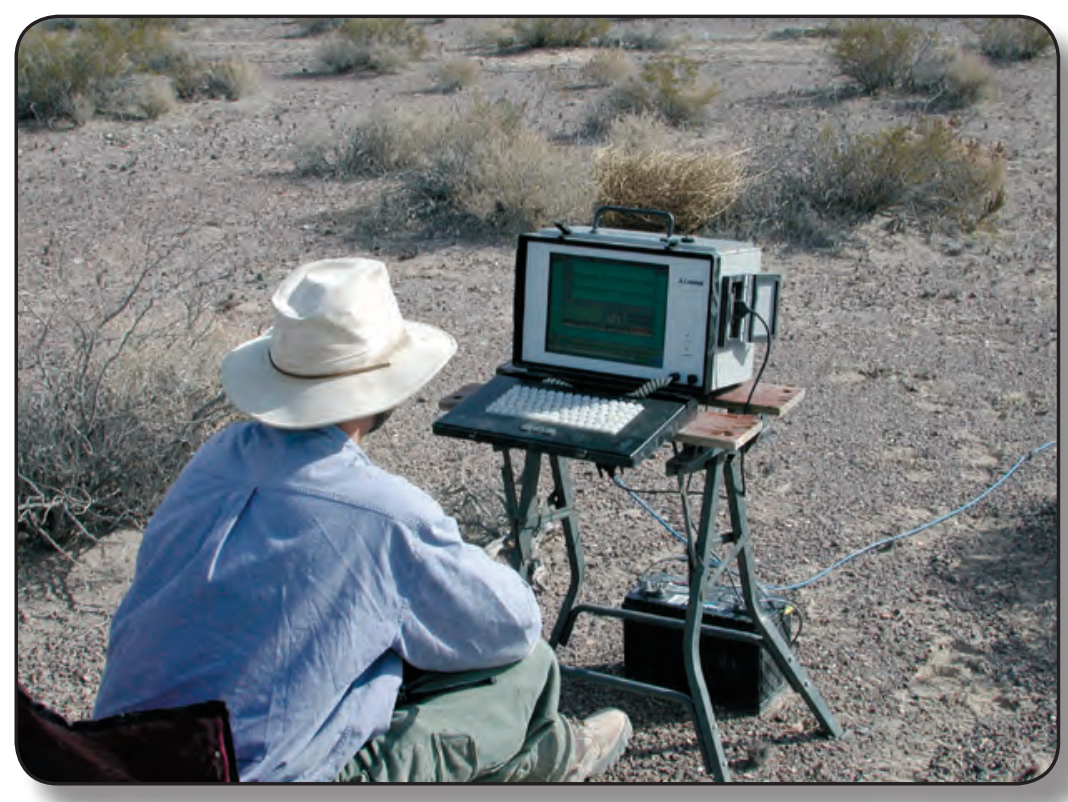

Circular 1310

U.S. Department of the Interior

U.S. Geological Survey 


\section{U.S. Department of the Interior DIRK KEMPTHORNE, Secretary}

\section{U.S. Geological Survey Mark D. Myers, Director}

U.S. Geological Survey, Reston, Virginia: 2007

For product and ordering information:

World Wide Web: http://www.usgs.gov/pubprod

Telephone: 1-888-ASK-USGS

For more information on the USGS - the Federal source for science about the Earth, its natural and living resources, natural hazards, and the environment:

World Wide Web: http://www.usgs.gov

Telephone: 1-888-ASK-USGS

Any use of trade, product, or firm names is for descriptive purposes only and does not imply endorsement by the U.S. Government.

Although this report is in the public domain, permission must be secured from the individual copyright owners to reproduce any copyrighted materials contained within this report.

Suggested citation:

Lucius, J.E., Langer, W.H., and Ellefsen, K.J., 2007, An introduction to using surface geophysics to characterize sand and gravel deposits: U.S. Geological Survey Circular 1310, 33 p. [available online at http://pubs.usgs.gov/circ/c1310/] 


\section{Contents}

Abstract.

Introduction

Scope of Report

Prospecting Techniques.

Traditional Techniques

Geophysical Surveys

Surface Geophysical Methods to Characterize Sand and Gravel Deposits.

Physical Properties.

Geophysical Characterization

Additional Information

Seismic Refraction and Reflection

DC Resistivity

Ground Penetrating Radar

Time-Domain Electromagnetic

Frequency-Domain Electromagnetic

Summary and Conclusions.

References and Selected Additional Reading.....

Glossary.

\section{Figures}

1-6. Photographs showing:

1. A portable, rugged computer used for controlling, monitoring, and recording seismic data

2. P-wave geophone and seismic cable

3. Hammer and plate as a P-wave seismic source.

4. A buried charge used as a P-wave seismic source.

5. S-wave seismic equipment 10

6. Generating S-waves with a light-weight S-wave source.

7. Interpretation of processed S-wave reflection data from light-weight source along road in figure 6 .

8-12. Photographs showing:

8. A control unit for a multielectrode resistivity system

9. A metal stake and a "smart" electrode strapped to it for a multielectrode resistivity system.

10. Some electrodes for a multielectrode resistivity system, at close spacing, and an all-terrain vehicle used to deploy the equipment

11. A capacitively coupled resistivity system towed by an all-terrain vehicle ..............13

12. Another view of a capacitively coupled resistivity system

13. Interpretation of a resistivity model from multielectrode resistivity data collected on alluvium on a flood plain

14. Interpretations of resistivity models for multielectrode resistivity data collected over a sand and gravel deposit in a glacial outwash channel in Minnesota 7 12 16 20 22 24 25 27
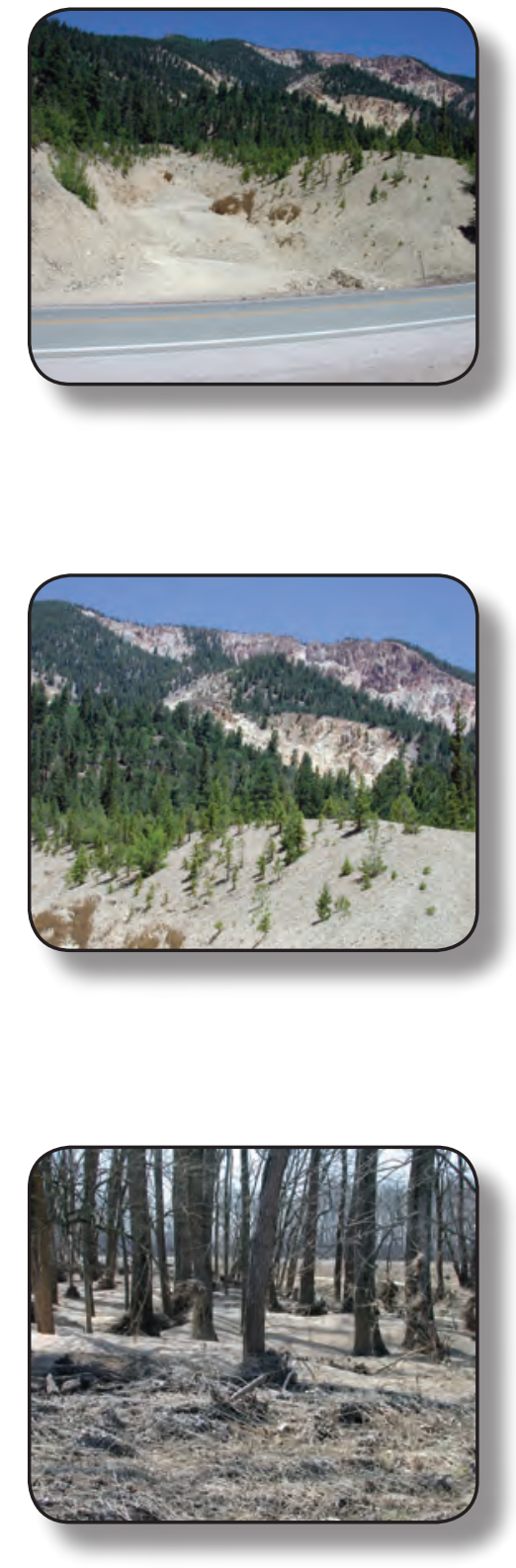
15-18. Photographs showing:

15. A ground-penetrating radar system with antenna separate from electronics and computer controls

16. A ground-penetrating radar system with antenna and electronics between the cart wheels and monitor and computer controls on the handle

17. Ground-penetrating radar equipment mounted on an all-terrain vehicle with antennas towed behind.

18. A 17-antenna ground-penetrating radar system.

19. Interpretation of ground-penetrating radar data collected near an active sand and gravel quarry.

20. Photograph showing collection of time-domain electromagnetic data.

21. Bedrock depth, in meters, determined using time-domain electromagnetic soundings on an alluvial flood plain

22-25. Photographs showing:

22. A frequency-domain conductivity meter 22

23. A fixed-frequency conductivity meter with fixed coil spacing on a plastic sled......23

24. A fixed-frequency conductivity meter with fixed coil spacing .................................23

25. A conductivity meter utilizing separate coils.

\section{Tables}

1. Physical properties and associated geophysical methods.

2. Typical approximate limits and ranges of selected properties of some common geologic material

3. Decision matrix of selected surficial geophysical methods for aggregate investigations

4. Comparison of approximate costs for selected geophysical methods .24

\section{Abbreviations}

$\mathrm{cm} \quad$ centimeter $\left(10^{-2}\right.$ meter $)$

DC direct (constant) electrical current

EM electromagnetic (coupled electric and magnetic fields)

FDEM frequency-domain electromagnetic (measurements are taken at a particular frequency)

$\mathrm{GHz} \quad$ gigahertz $\left(10^{9} \mathrm{~Hz}\right)$

GPR ground penetrating radar

$\mathrm{Hz} \quad$ hertz (one cycle per second, a measure of frequency)

$\mathrm{kHz} \quad$ kilohertz $\left(10^{3} \mathrm{~Hz}\right)$

$\mathrm{km} \quad$ kilometer (1,000 meters; about 3,281 feet or about 0.621 mile)

$\mathrm{m} \quad$ meter (about 3.281 feet, a measure of distance)

$\mathrm{m} / \mathrm{s} \quad$ meter per second (a measure of velocity)

$\mathrm{mS} / \mathrm{m}$ millisiemens per meter (same as $10^{-3} \mathrm{mho} /$ meter, a measure of electrical conductivity)

$\mathrm{mV} \quad$ millivolt $\left(10^{-3}\right.$ volt, a measure of electrical potential)

$\mathrm{MHz} \quad$ megahertz $\left(10^{6} \mathrm{~Hz}\right)$

ohm-m ohm-meter

$s \quad$ second (unit of time)

TDEM time-domain electromagnetic (measurements are taken sequentially in time) 


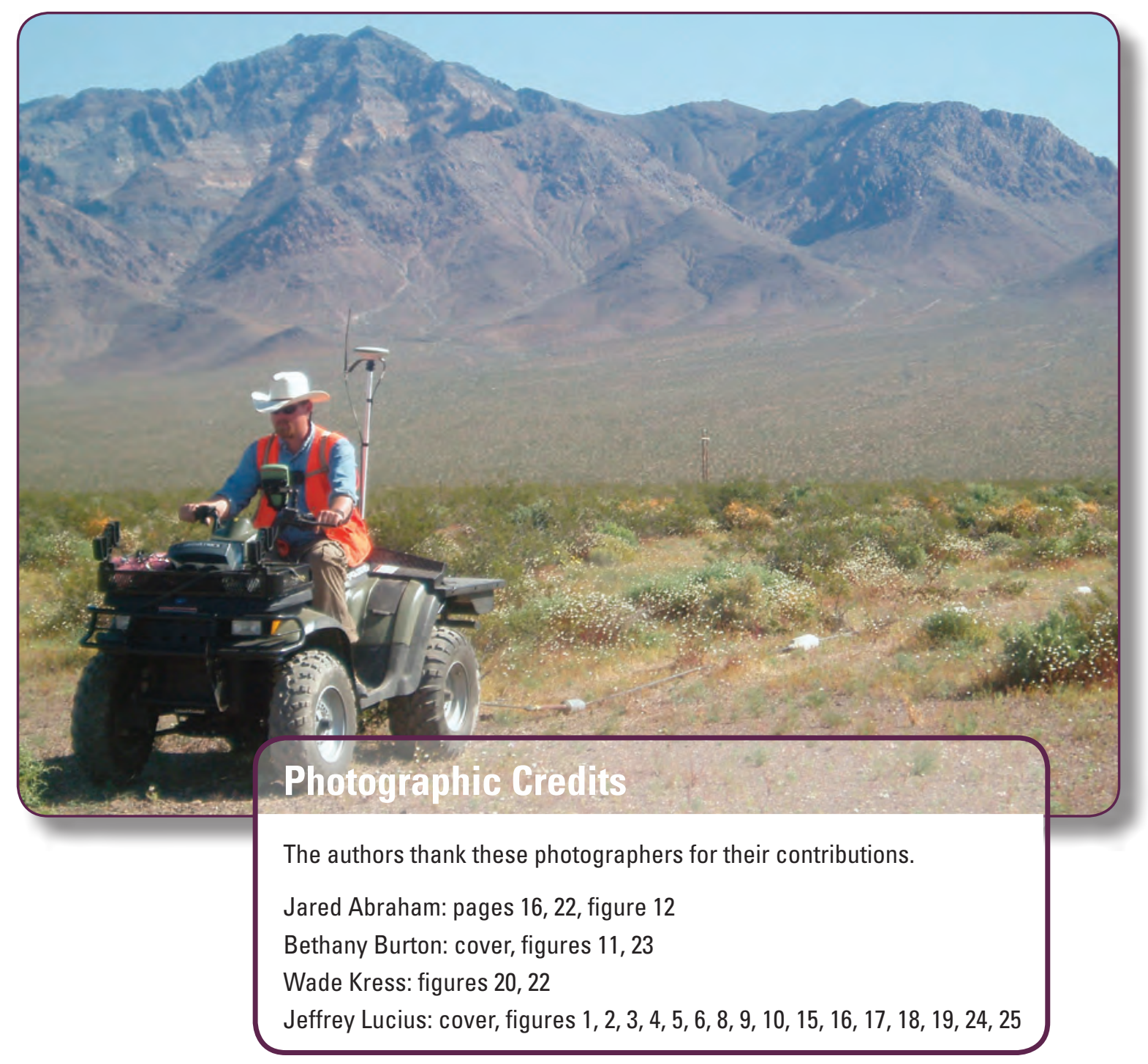



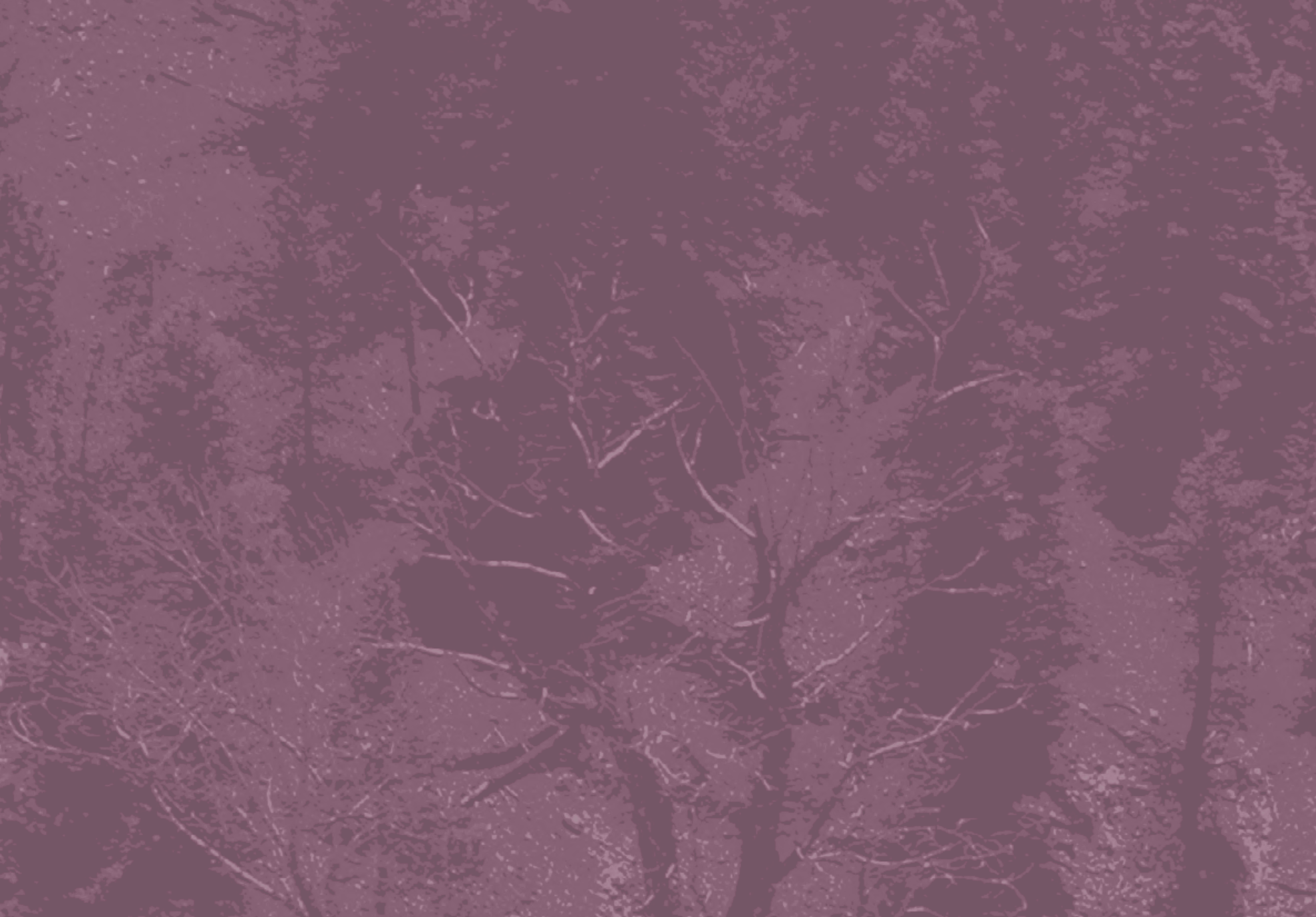

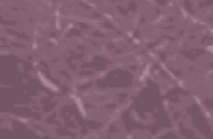

a

3 ing is

(2)

3

bix
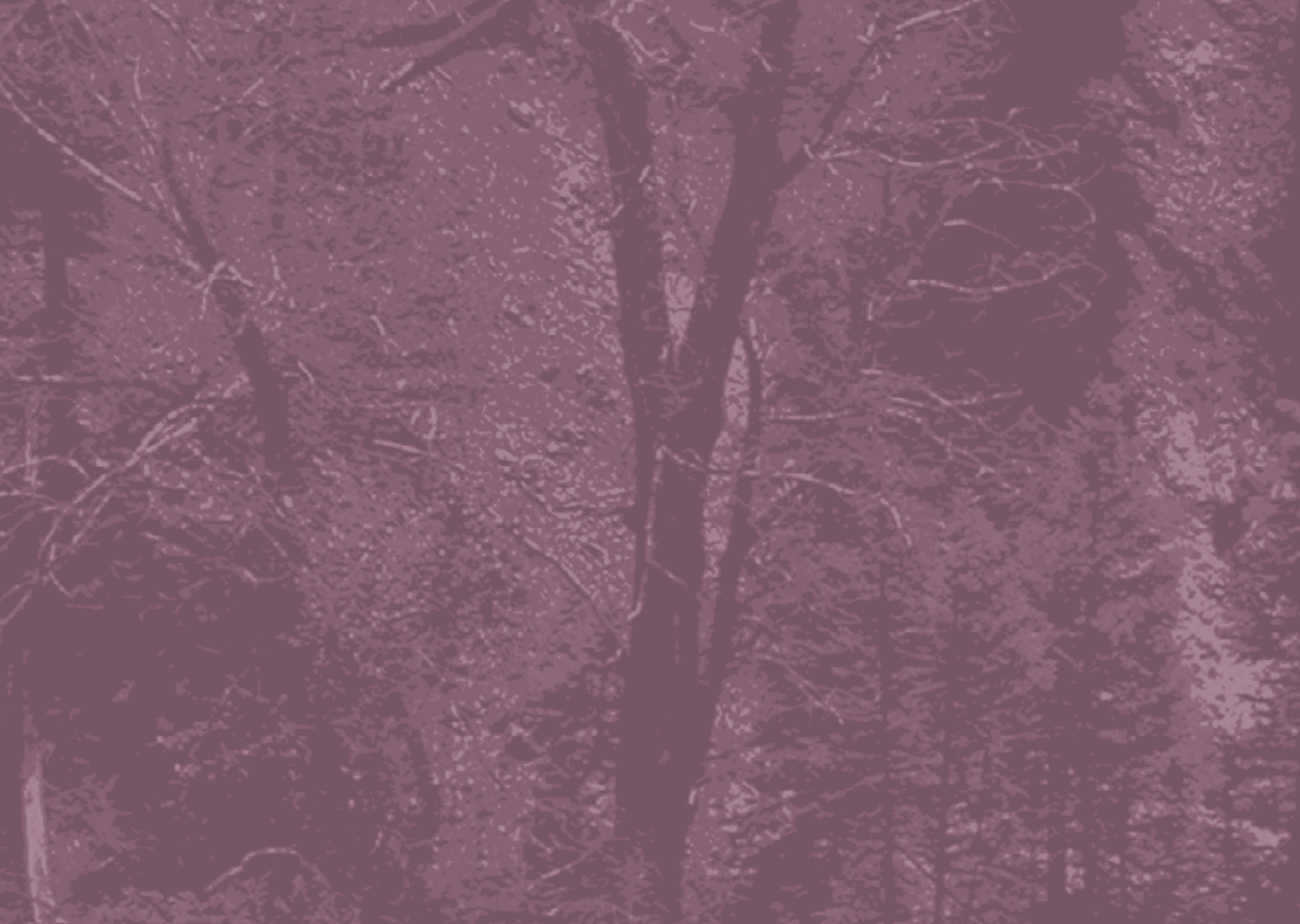

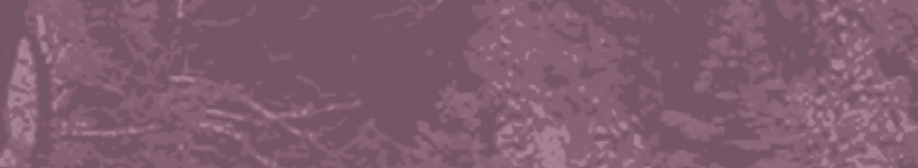
A

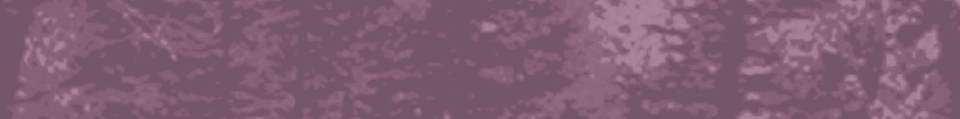

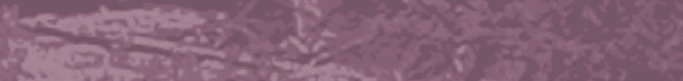

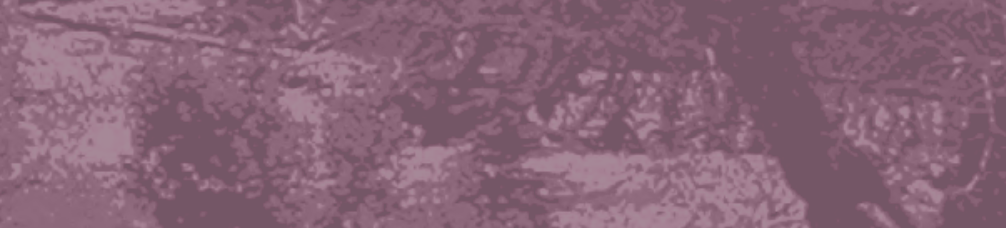
$9+\frac{1}{3}$

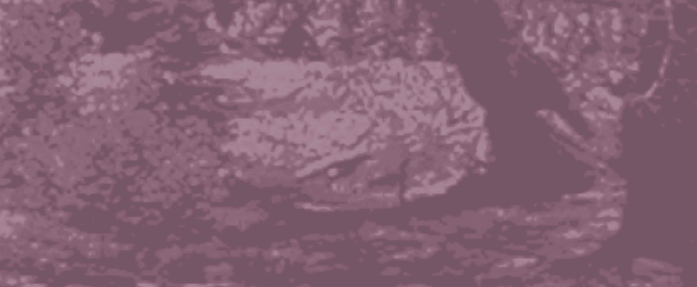
$\lim _{2}$

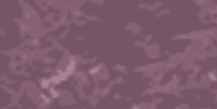

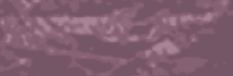

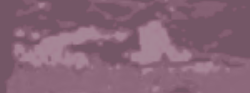

an-50

28

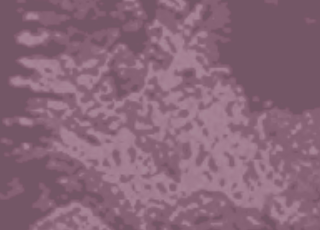

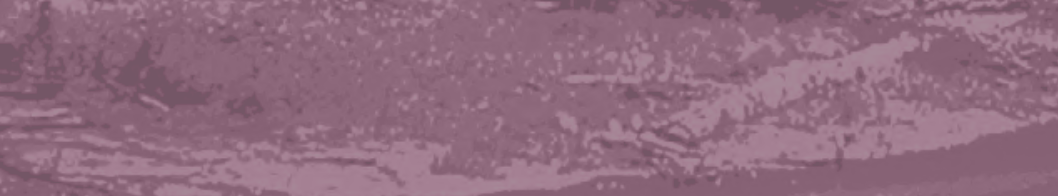




\title{
An Introduction to Using Surface Geophysics to Characterize Sand and Gravel Deposits
}

\author{
By Jeffrey E. Lucius, William H. Langer, and Karl J. Ellefsen
}

\section{Abstract}

$\mathbf{T}$ his report is an introduction to surface geophysical techniques that aggregate producers can use to characterize known deposits of sand and gravel. Five well-established and well-tested geophysical methods are presented: seismic refraction and reflection, resistivity, ground penetrating radar, time-domain electromagnetism, and frequency-domain electromagnetism. Depending on site conditions and the selected method(s), geophysical surveys can provide information concerning areal extent and thickness of the deposit, thickness of overburden, depth to the water table, critical geologic contacts, and location and correlation of geologic features. In addition, geophysical surveys can be conducted prior to intensive drilling to help locate auger or drill holes, reduce the number of drill holes required, calculate stripping ratios to help manage mining costs, and provide continuity between sampling sites to upgrade the confidence of reserve calculations from probable reserves to proved reserves. Perhaps the greatest value of geophysics to aggregate producers may be the speed of data acquisition, reduced overall costs, and improved subsurface characterization.

\section{Introduction}

and and gravel are components of a commodity referred to as natural aggregate, which also includes crushed stone. Together, sand, gravel, and crushed stone are the largest nonfuel mineral commodities produced in the United States and in the world. Annual production of aggregate in the United States during 2005 is about 2.91 billion tons (Bolen, 2006; Tepordei, 2006).

Of the total aggregate production, about 1.26 billion tons (43 percent) is construction sand and gravel. Sand and gravel are produced in every State in the United States from more than 6,300 operations, ranging in size from those that produce less than 25,000 tons per year to those that produce more than 2,500,000 tons per year (Bolen, 2006; Tepordei, 2006).

Sand and gravel are primarily used in construction to build and maintain urban, suburban, and rural infrastructures including highways, roads, bridges, parking lots, and sidewalks; commercial and residential buildings; factories and power-generating facilities; and water-supply and wastetreatment facilities. Our current quality of life would be impossible to maintain without sand and gravel.

\section{Scope of Report}

This report presents an introduction to surface geophysical techniques that aggregate producers can use to better characterize known deposits of sand and gravel. In some cases, geophysics might assist in the initial exploration for sand and gravel, but that is not the focus here. We assume the producer has already identified a potential deposit and needs a better understanding of its extent and quality. Nevertheless, geophysical surveys could be conducted during the test pitting and test drilling phases of exploration and characterization. In addition, geophysical measurements might be useful if problems are encountered during the extraction phase.

We focus on five well-established and well-tested surface geophysical methods that we judged suitable for characterizing sand and gravel deposits. To be considered, we required the method first to provide useful information; for example, the property measured is relevant to distinguishing a sand and gravel deposit from nearby deposits or rock. Second, we required the method to provide the correct combination of 
resolution, differentiation, and depth of investigation. Third, we required that cultural features (buildings, road traffic, radio transmitters, fences, buried utilities, surface power lines, and construction and manufacturing equipment) not have a significant effect on the method. Fourth, we required that the cost of data acquisition (labor and time), data processing, and equipment be reasonable. Finally, we required that useful information from the measurements be produced quickly.

This report is intended for geologists, geotechnical engineers, and aggregate producers who are unfamiliar with geophysical methods or with their application to the characterization of sand and gravel deposits. Readers are presented with an organized collection of information and options, but recommendations for specific sites or geologic environments are not made. Nevertheless, the information here is useful as an introduction to and summary of the field equipment, limitations, and benefits of the selected techniques. Some terms are defined in a Glossary at the end of this report.

\section{Prospecting Techniques}

\section{Traditional Techniques}

A number of manuscripts describe approaches to prospect for and characterize aggregate resources. Some older documents include those by Thoenen (1932), Lenhart (1960), Dunn and Cutcliffe (1971), Dunn (1983), Goldman and Reining (1983), and Langer (1988). More recent documents include Dunn (1991), Timmons (1994a-c, 1995), Goldman (1994), Langer and Knepper (1998), and Langer (2006).

Determining preliminary target areas for sand and gravel exploration commonly takes into account economic and social factors such as markets, transportation, land use, zoning regulations, and property ownership. Geologic exploration for sand and gravel deposits within target areas commonly begins with desktop studies utilizing existing data such as geologic maps and reports, satellite imagery, and aerial photographs. Field studies are conducted to collect new data and verify desktop analyses.

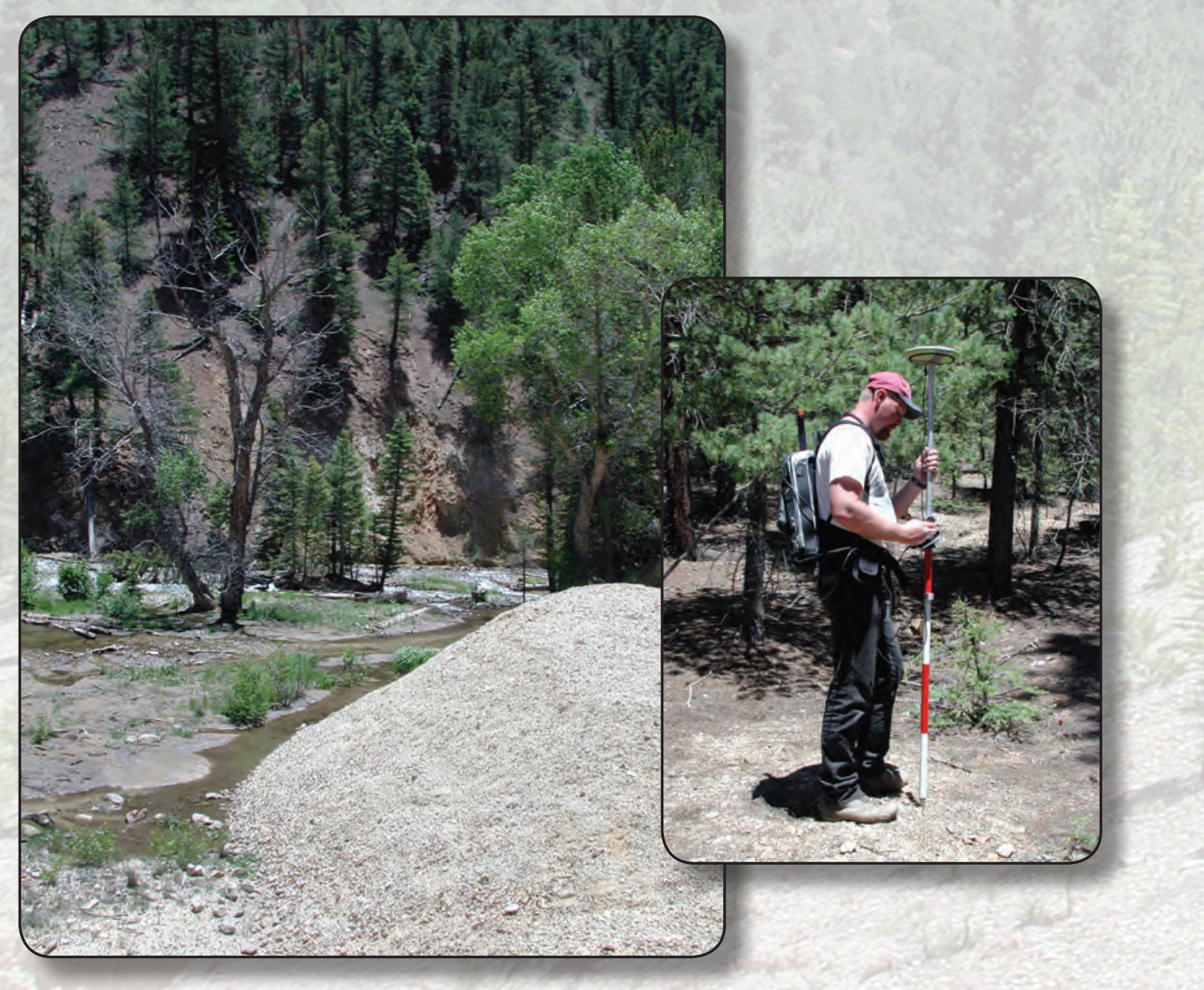


If reconnaissance studies indicate a target area worthy of further investigation, more detailed field studies may be conducted at specific sites. Systematic sampling is conducted to determine the areal extent, thickness, stratigraphic variation, and physical properties of deposits. Test pits, truck-mounted augers, and other truck-mounted drills commonly are used to determine these factors and to obtain samples to determine the properties of the sand and gravel. A power hoe can sample to about 4- or 5-meter depths, whereas truck-mounted augers can drill to depths of about 60 meters. Deposits having cobbles and boulders are difficult for augers to penetrate and may require the use of other drilling equipment. Sample spacing depends on the desired level of detail and confidence and typically ranges from $30 \mathrm{~m}$ in highly complicated areas to as much as $500 \mathrm{~m}$ in large areas of very simple geology.

\section{Geophysical Surveys}

In the most general sense, geophysics measures all aspects of the physics of the Earth, atmosphere, and outer space. This report focuses on surface geophysical methods that obtain information about the spatial distribution of subsurface physical properties that can be used to characterize sand and gravel deposits.

Only the electrical resistivity geophysical method was used to explore for sand and gravel prior to the late 1930s (Patterson, 1937). Since then, geophysical techniques and data processing have advanced significantly. Now, a number of geophysical methods can be used to help detect, map, and characterize sand and gravel deposits. In addition to ground-based geophysics, airborne remote sensing techniques have been applied to aggregate resources; see, for example, Knepper and others (1995).

Currently, ground-based geophysical methods to characterize sand and gravel deposits include electrical methods, electromagnetic methods, ground penetrating radar, and seismic methods (Ellefsen and others, 1998; Ellefsen and others, 2005). These will be discussed in the next section. We consider potential field methods and radioactivity methods generally unsuitable for sand and gravel characterization, and, except in the Glossary, we do not discuss them in this report.

Depending on site conditions and the selected method(s), geophysical surveys can provide information on the following:

- areal extent and thickness of the deposit,

- thickness of overburden,

- depth to the water table,

- critical geologic contacts, and

- location and correlation of geologic features.
Additionally, geophysical measurements can be taken where closely spaced geological changes might be undetected by drilling, such as areas of suspected buried channels.

Ground-based geophysical surveys can be conducted prior to intensive drilling to help:

- locate auger or drill holes,

- reduce the number of drill holes required,

- calculate stripping ratios to help manage mining costs, and

- provide continuity between sampling sites to upgrade the confidence of reserve calculations from probable reserves to proved reserves.

The surveys can be conducted to provide subsurface detail where digging test pits, boring, or drilling are encumbered because of limited access, such as in areas of active cropland or forested land, or where auger trucks or drill rigs are unable to navigate due to the ground surface being soft, muddy, or covered with water. They can also be conducted where the geologic properties of the target deposit may restrict boring; for example, where deposits contain cobble-sized or larger clasts. Additional problems related to drilling are described by Timmons (1995).

The results of geophysical surveys are maps or cross sections showing the spatial variations in geophysical properties, such as the speed of seismic waves. Additional information is needed to translate geophysical properties into meaningful geologic properties such as the thickness of sand or gravel. This additional information may come from driller's logs or geologic mapping, for example. Thus, geophysical surveys may be considered as a complement to, but not a replacement for, traditional methods of exploration.

Perhaps the greatest value of geophysics to aggregate producers may be the speed of data acquisition, reduced overall costs, and improved subsurface characterization. The greatest deterrent to the use of geophysics for sand and gravel characterization is likely both a lack of understanding and confidence in the methods and the subjectiveness of interpretations. We address these issues, and more, in the next section.

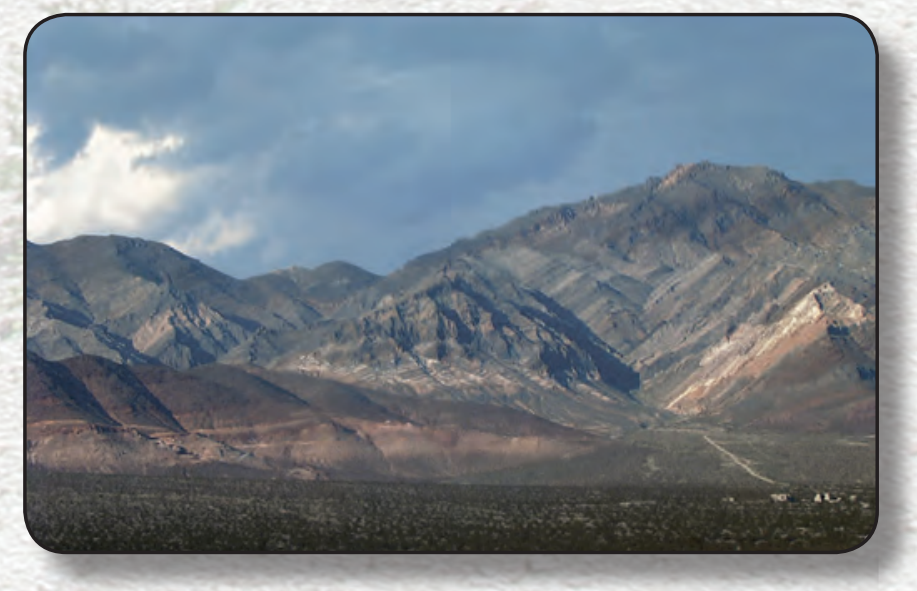




\section{Surface Geophysical Methods to Characterize Sand and Gravel Deposits}

\section{Physical Properties}

Table 1 presents selected physical properties and their related field or phenomenon and the generalized geophysical method associated with each one.

Sand and gravel deposits have specific combinations of physical properties. These combinations may or may not be sufficiently different from other types of adjacent sediment or rock for geophysical methods to identify the sand and gravel. The properties that most commonly distinguish sand and gravel from surrounding material are electrical conductivity, dielectric permittivity, seismic velocity, and density. Magnetic susceptibility and radioactivity might differentiate the sand and gravel deposit if the source rock for the sand and gravel is much different from the surrounding rock. Differences in electrical conductivity are usually caused by clays, porosity, the amount of water filling the pore space, and the conductivity of the pore water. The bulk dielectric permittivity of the ground is most influenced by small changes in water content and by packing or layering. Seismic velocity is affected by the stiffness or hardness of the ground (described using elastic properties) and density, which quite often are very different between unconsolidated sand and gravel and indurated bedrock.

Dry sand and gravel have low electrical conductivity $(5 \mathrm{mS} / \mathrm{m}$ or less, or a resistivity of $200 \mathrm{ohm}-\mathrm{m}$ or more), low relative dielectric permittivity (RDP) (below 6 to 9), and low seismic velocity (often less than $1,000 \mathrm{~m} / \mathrm{s}$ for P-waves).

Saturated sand and gravel have a relatively high electrical conductivity $(20 \mathrm{mS} / \mathrm{m}$ or more, or resistivity of perhaps $50 \mathrm{ohm}-\mathrm{m}$ or less), intermediate relative dielectric permittivity (above 14 to 16 ), and relatively high seismic velocity (greater than $1,500 \mathrm{~m} / \mathrm{s}$ for P-waves).

Bedrock usually has a seismic velocity of several thousand $\mathrm{m} / \mathrm{s}$ (P-waves). However, the electrical conductivity and dielectric permittivity may be similar to or different from that of sand and gravel. If the bedrock is limestone or sandstone, the electrical resistivity commonly will be in the hundreds of ohm-meters.

Typical values for selected properties of some common geologic materials are shown in table 2 .

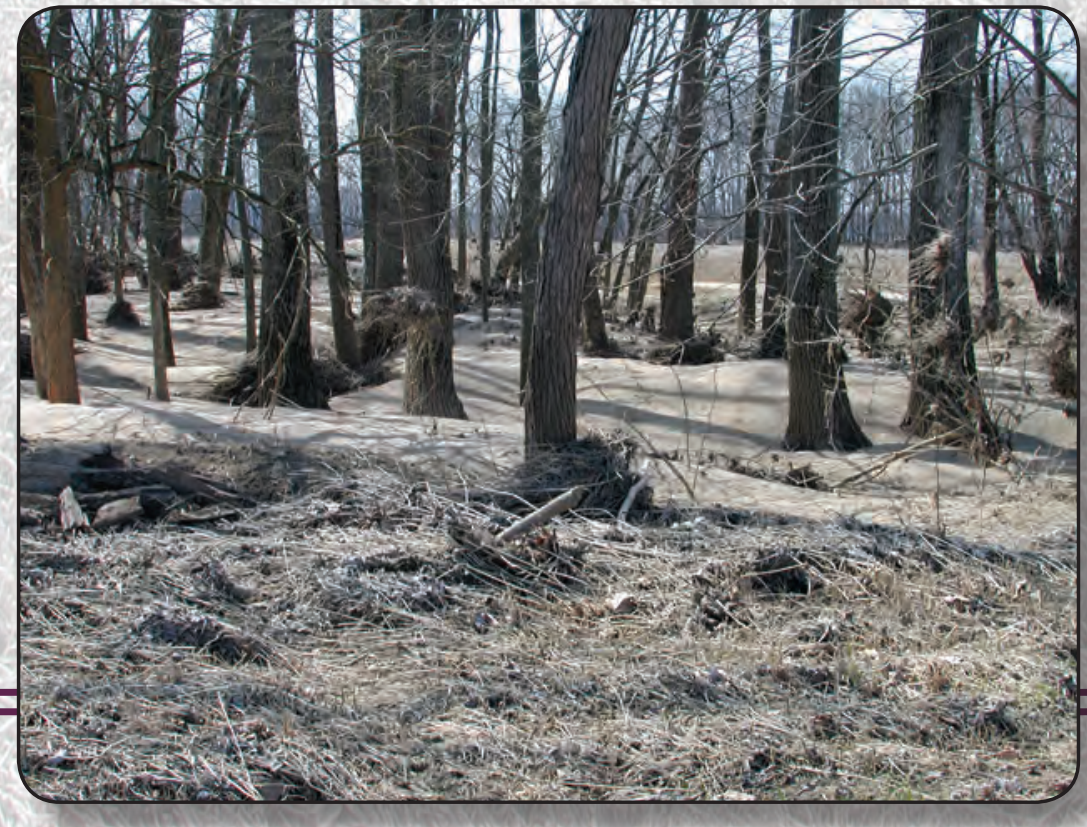


Table 1. Physical properties and associated geophysical methods.

\begin{tabular}{|l|l|l|}
\hline \multicolumn{1}{|c|}{ Physical property } & \multicolumn{1}{c|}{ Field or phenomenon } & \multicolumn{1}{c|}{ Geophysical method } \\
\hline Density & Gravity & Gravity \\
\hline Magnetic susceptibility & Magnetism & Geomagnetic \\
\hline Electrical conductivity & Electricity, low-frequency electromagnetism & Electrical, electromagnetic \\
\hline Dielectric permittivity & High-frequency electromagnetism & Electromagnetic \\
\hline Elasticity & Elastic waves & Seismic \\
\hline Radioactivity & alpha, beta particles and gamma rays & Radioactivity \\
\hline
\end{tabular}

Table 2. Typical approximate limits and ranges of selected properties of some common geologic material (adapted from Sheriff, 1991; Reynolds, 1997; and ASTM Standard D 5777-00).

[mS/m, millisiemens per meter; ohm-m, ohm-meter; $\mathrm{m} / \mathrm{s}$, meter per second; <, less than; >, greater than]

\begin{tabular}{|c|c|c|c|c|}
\hline Material & $\begin{array}{c}\text { Conductivity } \\
\text { (ms/m) }\end{array}$ & $\begin{array}{c}\text { Resistivity } \\
\text { (ohm-m) }\end{array}$ & $\begin{array}{c}\text { Relative dielectric } \\
\text { permittivity }\end{array}$ & $\begin{array}{c}\text { P-wave velocity } \\
(\mathrm{m} / \mathrm{s})\end{array}$ \\
\hline Soil & $<10$ to $>50$ & $<20$ to $>100$ & Low to high & 100 to 500 \\
\hline Dry sand and gravel & $<5$ & $>200$ & Low & 450 to 950 \\
\hline Saturated sand and gravel & $>20$ & $<50$ & Medium & 1,250 to 1,850 \\
\hline Clay & 10 to 200 & 5 to 100 & Medium to high & 900 to 2,700 \\
\hline Sandstone & 1 to 20 & 50 to 1,000 & Low & 1,800 to 4,000 \\
\hline Igneous rock & $<1$ & $>1,000$ & Low & 4,500 to 6,000 \\
\hline Metamorphic rock & $<1$ & $>1,000$ & Low & 3,000 to 7,000 \\
\hline
\end{tabular}

\section{Geophysical Characterization}

Geophysical characterization of a sand and gravel deposit involves measuring the physical properties previously mentioned, or contrasts of these properties, in order to determine the thickness of overburden, depth to bedrock, and thickness and lateral extent of the deposit. Geophysical characterization can help determine the limits and volume of the deposit, depth to the water table in or below the deposit, and sometimes stratigraphy and depositional environment related to the deposit. In some cases, geophysics can determine deposit quality with respect to the amount of fine material and porosity.
Geophysical methods can be faster and less expensive than additional drilling and trenching and can provide continuous profiles and three-dimensional information. The depth of investigation for most methods is suitable for exploration and characterization of many sand and gravel deposits. In addition, intrusion and damage to the environment usually are limited.

There are limitations to the information surface geophysics can provide. Generally, geophysical measurements cannot define precise rock or sediment lithology, mineralogy, hardness, or chemical reactivity. On the other hand, geophysics can provide some physical property information, such as the distribution of electrical resistivity and the location of 


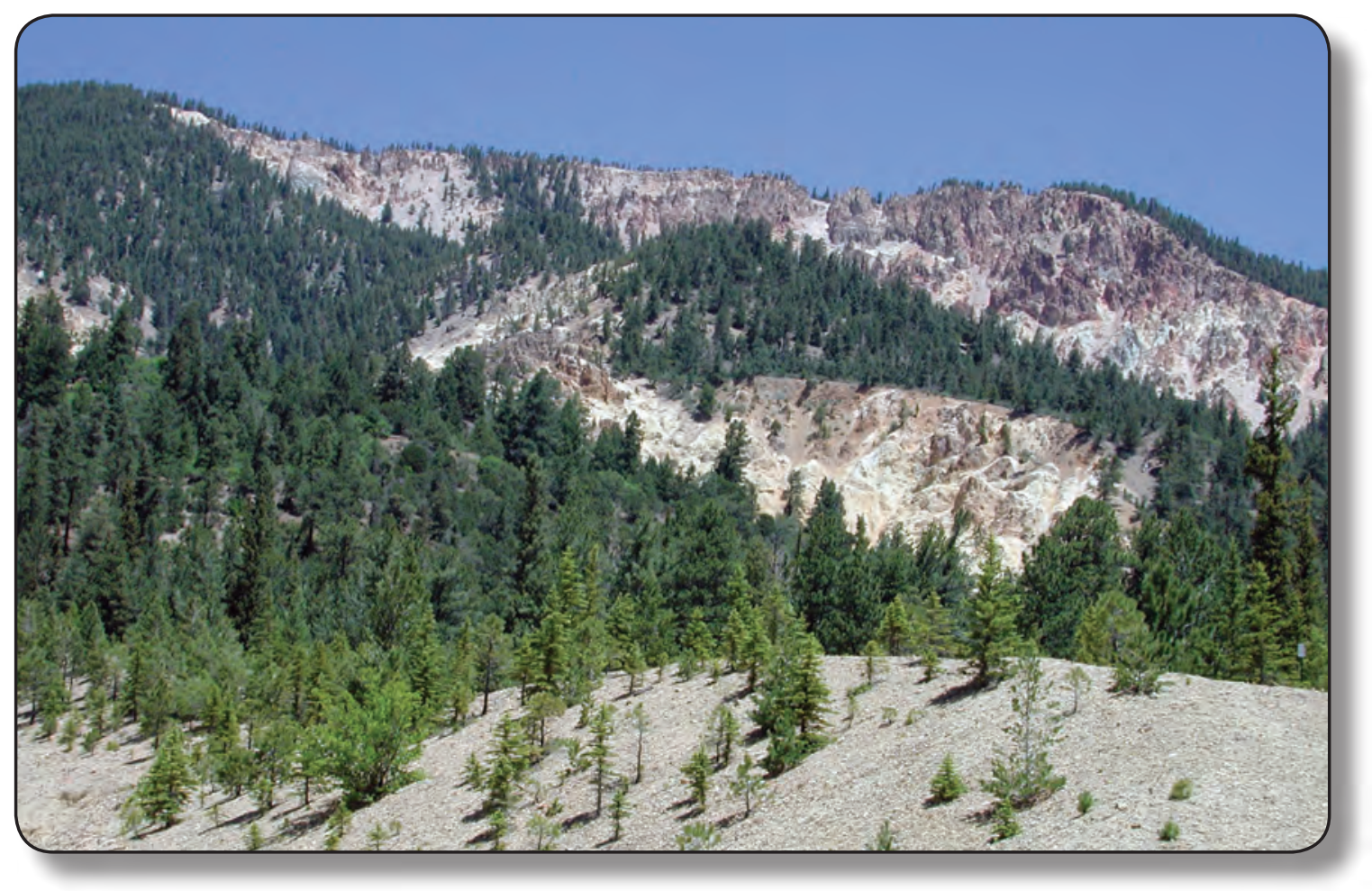

lithologic or hydrologic boundaries. However, a particular set of field measurements often cannot be associated with a unique model of subsurface conditions; that is, there is an inherent ambiguity to all geophysical measurements. This ambiguity can be reduced with the use of multiple geophysical methods and with additional geological information such as borehole data.

Given the limitations and benefits of geophysical methods, successful application of a particular method is always site specific and quite often dependent on the experience and judgment of the geophysicist.

In subsequent sections we describe five surface geophysical methods that can be practical for sand and gravel deposit characterization. The information here is drawn from our own experience and from many of the references listed at the end of this report. Table 3 provides an evaluation of the applicability of the selected methods for some of the problem types encountered when characterizing sand and gravel deposits. Some of the basic principles and theory for each method are discussed here, with additional details in the Glossary. We show how each method can be used to define or reveal some characteristic of sand and gravel deposits. We do not discuss the mathematical theory behind the method, the details of performing a survey, processing and interpreting field data, or the cost of equipment or services. We do discuss the specific benefits and limitations of each method. We also present some examples of equipment and results in the figures, which are explained in the figure captions rather than in the text.

Table 3. Decision matrix of selected surficial geophysical methods for aggregate investigations (adapted from U.S. Army Corps of Engineers, 1995).

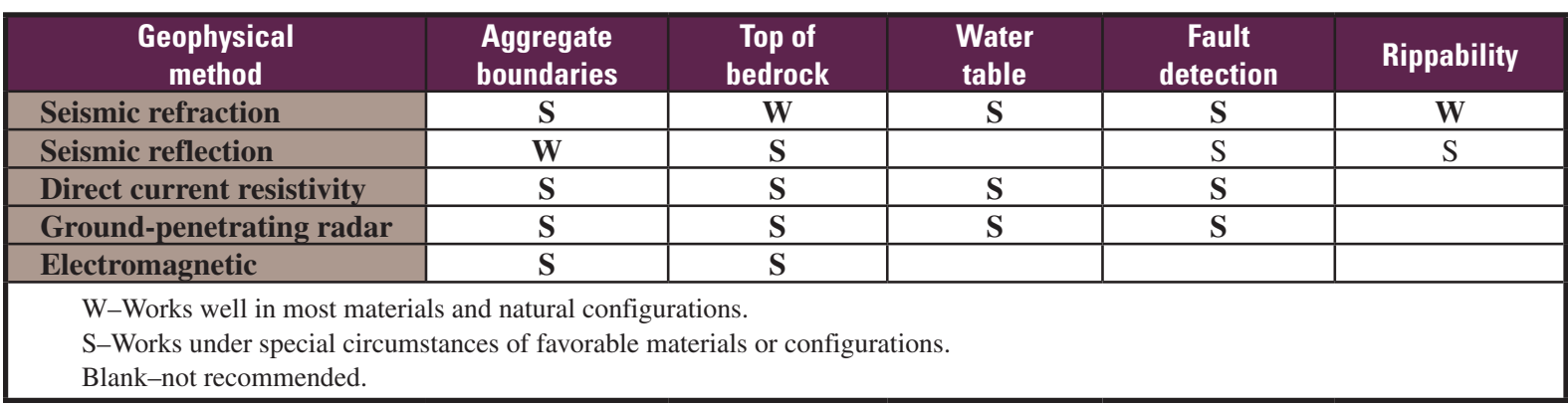




\section{Additional Information}

Because equipment models change regularly, software is improved or replaced, and prices change or are negotiated, we have refrained from mentioning specific equipment or software manufacturers, listing prices of equipment or rental fees, or providing a directory of retailers. Readers can collect some of this information by using popular search engines on the Internet. However, the geophysical methods themselves are enduring. The reader can learn more about the theory and application of geophysics in "applied geophysics" books such as Telford and others (1990), Reynolds (1997), Sharma (1997), Butler (2005), and Burger and others (2006). Some on-line general sources are:

\section{http://www.cflhd.gov/agm/solutionMatrix/index.htm}

maintained by the Federal Lands Highway Program of the U.S. Department of Transportation, Federal Highways Administration,

http://www.usace.army.mil/inet/usace-docs/eng-manuals/ em1110-1-1802/toc.htm

provided by the U.S. Army Corps of Engineers, and

\section{http://galitzin.mines.edu/INTROGP/}

which is a technical introduction available at the Colorado School of Mines Web site. The "References and Selected Additional Reading" section of this report lists some additional sources.
The American Society for Testing and Materials (ASTM, http://www.astm.org/) publishes guides for using many geophysical techniques, including, for example, the following.

- D6429-99 Standard Guide for Selecting Surface Geophysical Methods

- D6431-99(2005) Standard Guide for Using the Direct Current Resistivity Method for Subsurface Investigation

- D6432-99(2005) Standard Guide for Using the Surface Ground Penetrating Radar Method for Subsurface Investigation

- D5777-00 Standard Guide for Using the Seismic Refraction Method for Subsurface Investigation

- D6639-01 Standard Guide for Using the Frequency Domain Electromagnetic Method for Subsurface Investigation

- D6820-02 Standard Guide for Use of the Time Domain Electromagnetic Method for Subsurface Investigation

- D7128-05 Standard Guide for Using the Seismic Reflection Method for Shallow Subsurface Investigation

These guides summarize the technique, equipment, field procedures, data processing, and interpretation methods for the various geophysical techniques.

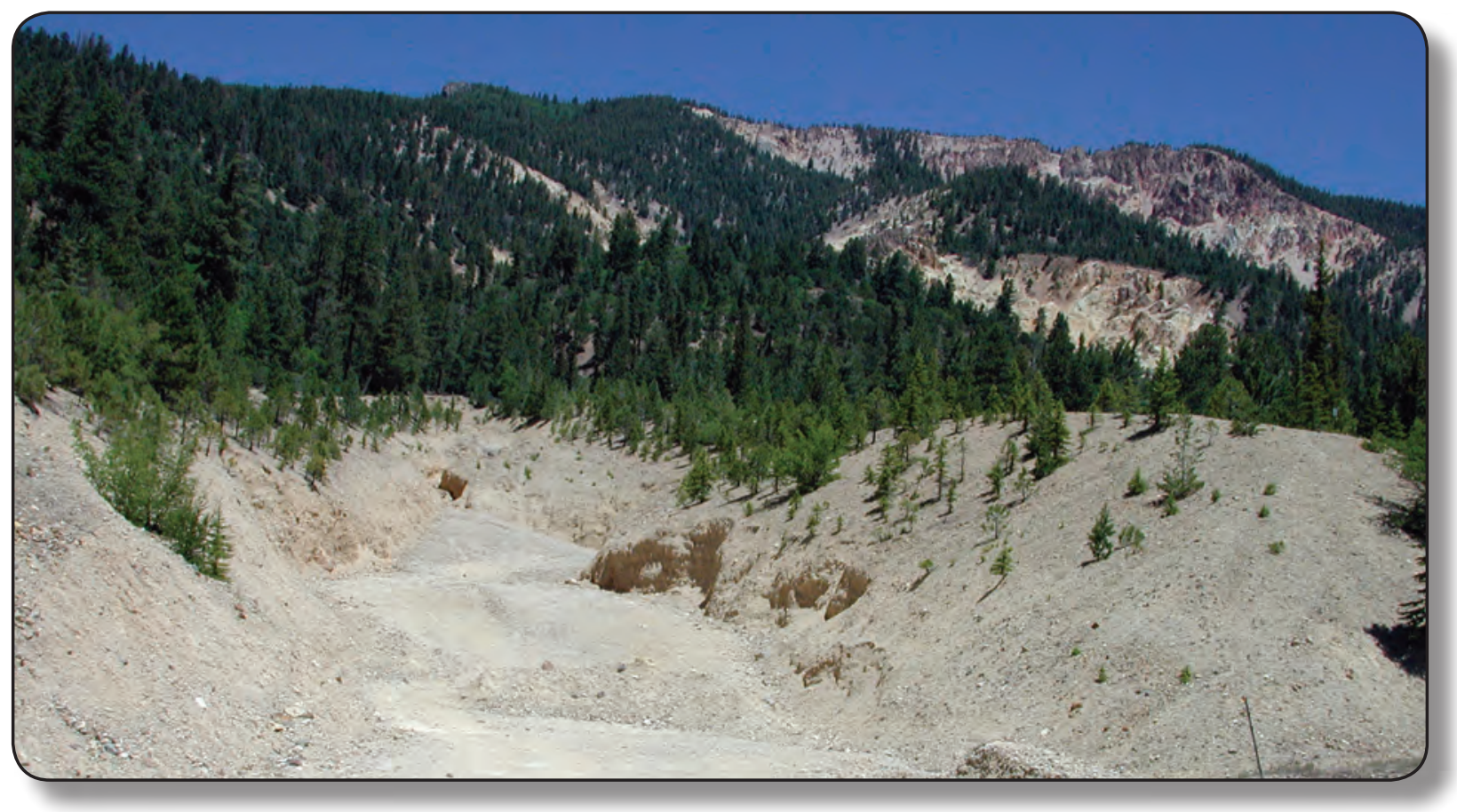




\section{Seismic Refraction and Reflection}

\section{Overview}

Seismic methods were developed early in the 20th century. However, it was not until the 1980s and the advent of affordable digital signal processors and personal computers that seismic investigations could be conducted for environmental and engineering purposes. Outside of oil and mineral exploration, seismic methods are used to determine depth and lateral extent of layers, thickness and volume of deposits, and thickness of overburden. Potentially, rock quality (rippability) can be determined from seismic velocity.

Seismic methods depend on the transmission of strain energy, as an elastic wave (called a seismic wave) through a medium. Elastic waves are generated by an external force being applied to a medium. The external force in shallow seismic methods is often a sledgehammer striking a plate or block, a weight dropped or accelerated onto the ground or plate, a slug or bullet fired into a shallow hole, or a small explosive charge buried in a hole. Seismic wave energy is a form of mechanical energy (particle motion).

The two types of seismic waves discussed here are P-waves and S-waves. In all media, P-waves travel faster than S-waves. The velocities of these waves are determined by both the elastic properties and density of the ground. Seismic waves travel slower in unconsolidated sediments and faster in rock. The elastic properties and density of the ground influence seismic waves.

Seismic wave detectors are called geophones and convert ground vibrations (or motion) into an electrical signal. Geophones are usually distributed in straight lines across the study area. The electrical signal from the geophones is converted into digital values using modular 12-, 24-, or 48-channel, high-resolution, signal-enhancement seismographs. Some seismographs can be linked together to increase the number of geophones. Portable computers record the seismograph data. Field crews for shallow surveys need a minimum of two to four persons (figs. 1-7).

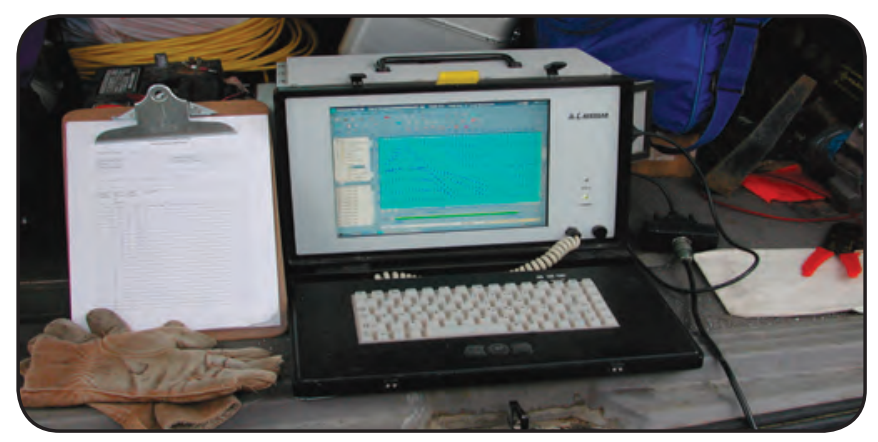

A Figure 1. A portable, rugged computer used for controlling, monitoring, and recording seismic data.

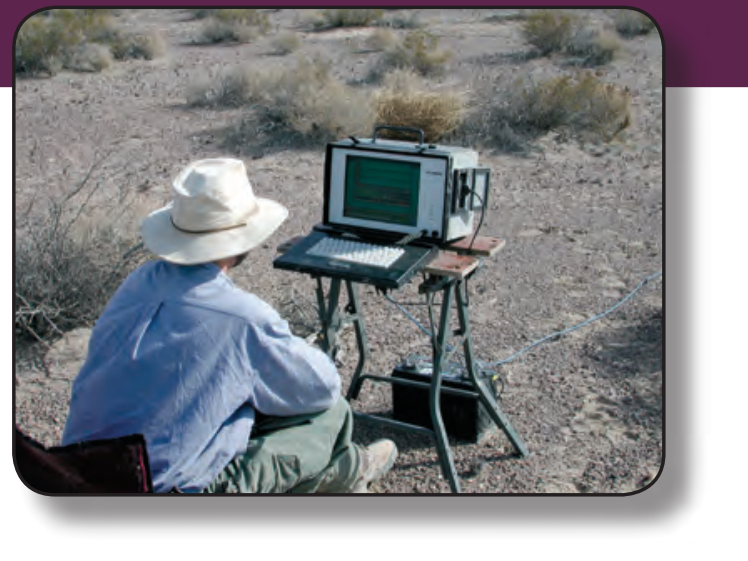

Refraction and reflection are two seismic techniques for interpreting seismic wave measurements. In the refraction method, the arrival time of the first waves to reach the geophones is measured. From these first arrivals, the interpreter determines the depth to the refractor (an underground layer) and seismic wave velocity in the media at various places along the survey line. As many as three or four layers can usually be identified using standard interpretation methods. An image of continuously variable subsurface seismic velocities can be produced using inversion techniques. With current technology, refraction is often better than reflection for determining bedrock depths less than $20 \mathrm{~m}$.

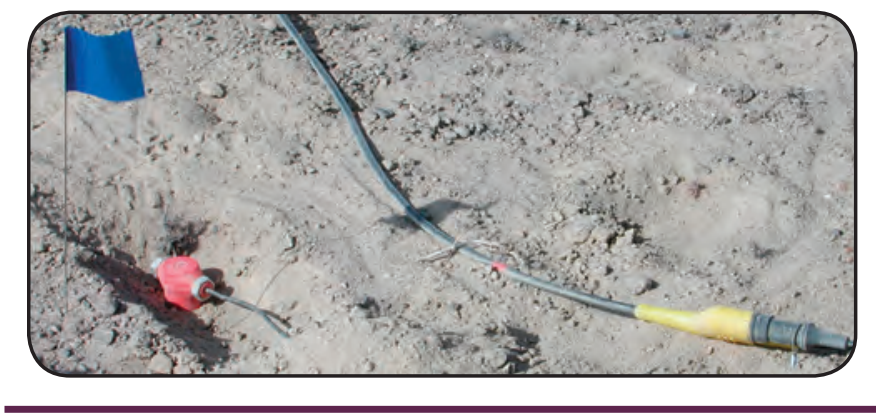

A Figure 2. P-wave geophone and seismic cable.

In the reflection method, the interpreter must find in the seismic record waveforms that are reflections from subsurface layers. Generally, these reflections occur in the record later than refractions, and they are often mixed with surface waves and noise. This can make reflections hard to identify, so the data must be processed much more extensively than refraction data. In addition, after the data are processed to find the reflection, additional processing must occur to determine the seismic velocities and then to transform the data into a cross section showing the geometry of the subsurface structures. When bedrock is $20 \mathrm{~m}$ or deeper, reflection may be more appropriate than refraction.

For both methods, interpretation is in terms of subsurface boundaries between regions or layers with different seismic velocities that result from changes in elastic properties and (or) density. 


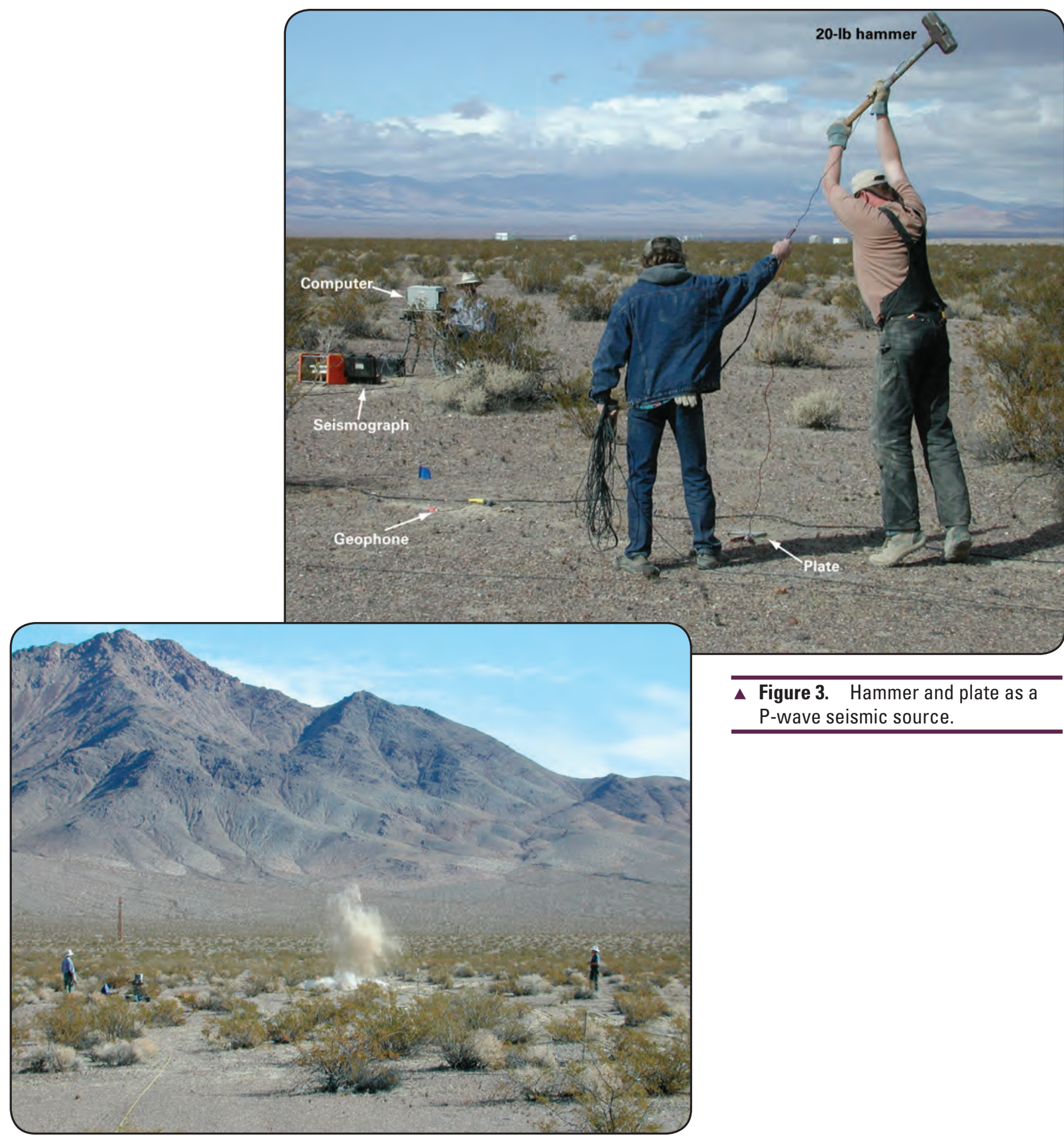

Figure 4. A buried charge used as a P-wave seismic source. 


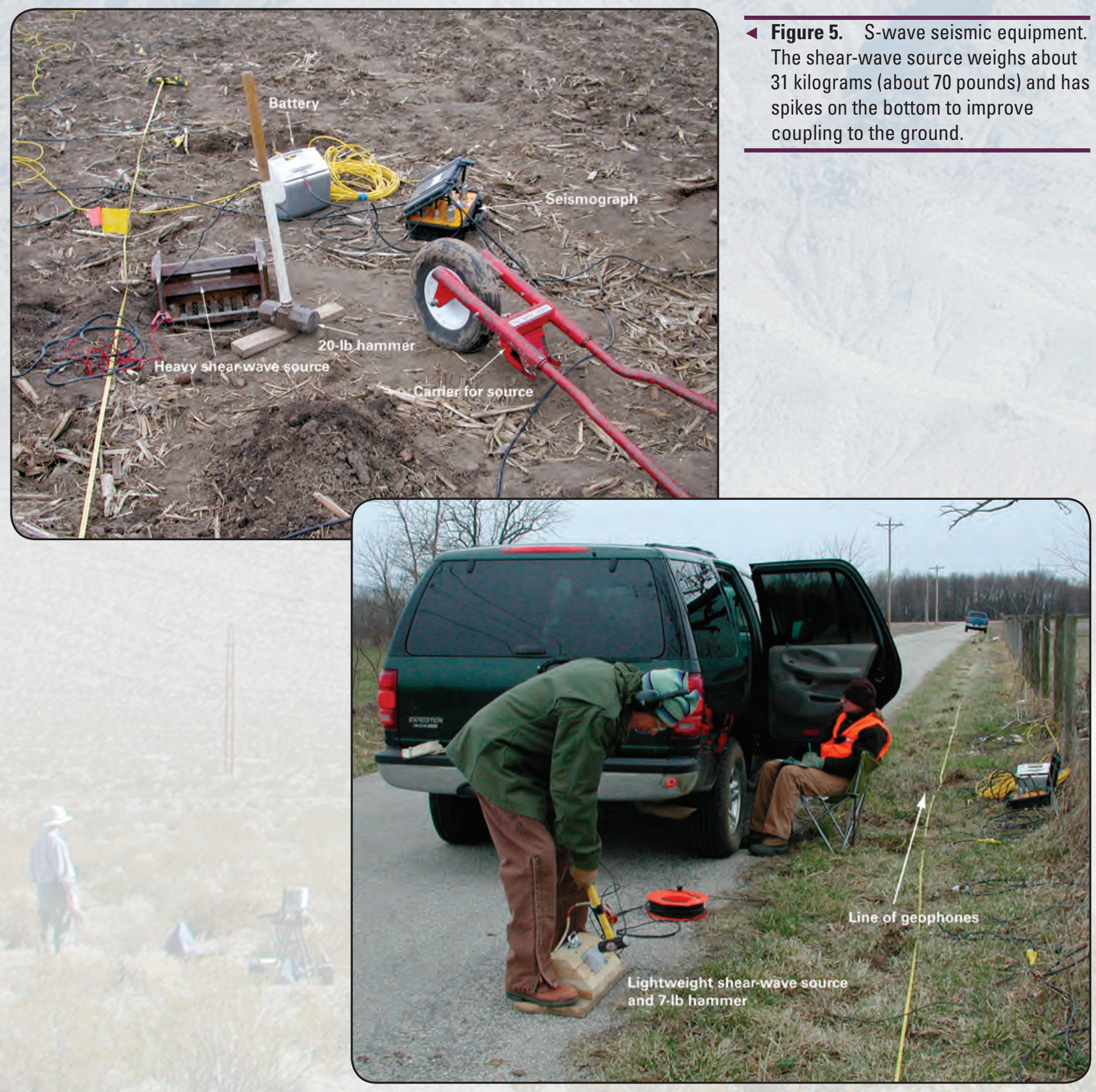

\ Figure 6. Generating S-waves with a light-weight S-wave source. The recording unit, shown in figure 1 , is in the nearby truck. 


\section{Benefits}

Despite the generally much higher cost of the seismic method, the results can be very useful in characterizing sand and gravel deposits, especially for determining depth to bedrock. Seismic methods can produce near-continuous, detailed coverage of sections of the ground, detecting both lateral and vertical variations. Resolution can be as small as several meters, depending on source and geophone frequency, the method used, and the ground conditions. Seismic methods can be very effective in mapping bedrock under alluvial fill, as well as some stratigraphic and depositional features, and sometimes the water table (if using P-waves). When additional information is available, the methods may be able to tell the difference between clay-rich and clay-poor sediments. In areas that are too conductive for effective ground-penetrating radar use, and where electromagnetic techniques cannot provide adequate resolution, seismic methods can be an alternative geophysical method for exploration.

\section{Limitations}

Despite some significant advantages, seismic methods have noteworthy disadvantages. For example, ambient sound and vibrations from equipment, vehicles on roads, persons walking near the geophones, wind, and rain add significant noise to the recorded data. One of the most important disadvantages can be the expense of processing and interpreting large volumes of reflection data. Refraction data require somewhat less processing. Seismic equipment also can be relatively expensive and requires labor-intensive field deployment techniques. In fact, seismic data collection is the most labor intensive of the methods discussed here. In general, the seismic methods can be much more expensive to use than the other methods mentioned in this report because of large crew sizes, expensive equipment, and relatively slow data collection and data processing. Data collection can be faster and less expensive with the refraction method because there are often far fewer seismic source locations.

The seismic methods also have a safety issue that other methods do not have: the seismic source. Because sources must direct substantial force into the ground, caution and training are required, particularly with projectile sources (shotgun or rifle), powered sources (heavy, machineaccelerated drop weights), and buried charge sources (explosives). Even with a sledgehammer and plate, the operator must wear hearing protection and beware of hammer impacts as well as moving a heavy target plate or block. Other safety issues include the hazards of operation near roads, operating vehicles off road, and the danger of lightning strikes on the cables.

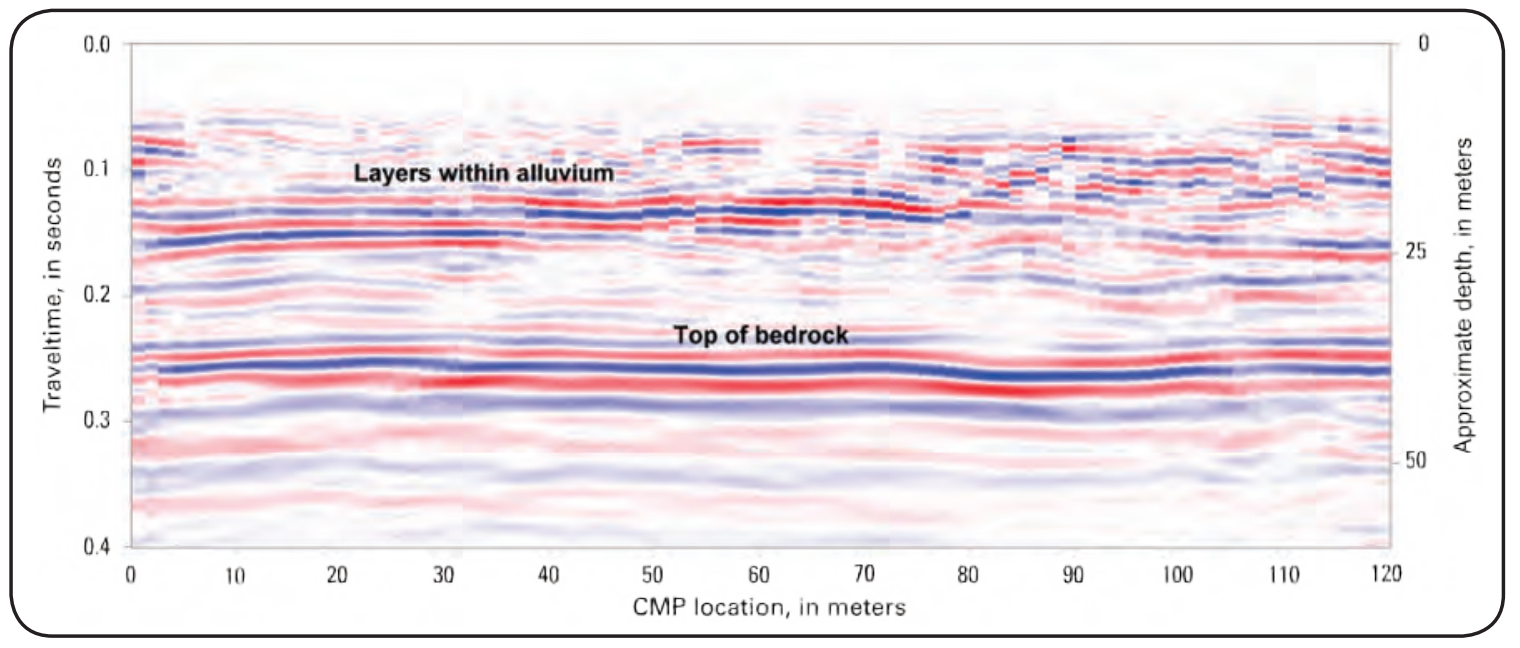

A Figure 7. Interpretation of processed S-wave reflection data from light-weight source along road in figure 6. 


\section{Resistivity}

\section{Overview}

The resistivity method was developed early in the 1900 s and was in widespread use because of its simplicity and good results. Four metal-stake electrodes are driven into the ground. Electric current is introduced using two of the electrodes, and the electric potential is measured between the other two electrodes. With the help of computer modeling, a representative resistivity structure of the earth is determined. Within the limits of the technique's resolution, the method is proven and reliable in identifying areas that are relatively conductive (for example, water-saturated sediments or fine-grained/clay-rich regions) compared to areas that are relatively resistive (such as relatively dry sediments or coarse-grained regions).

Presently, resistivity surveys are used in a wide variety of mineral, engineering, geologic, and environmental site investigations. With regard to sand and gravel deposits, the resistivity method can detect depth and lateral extent of coarse-grained (sand or gravel) compared to fine-grained (clay) layers, wet or dry sediments, depth to water table, and depth to bedrock.

The arrival of the personal computer in the 1970s and 1980s made interpretation easier and gave better quantitative results than visual curve-matching. Data-collection systems were developed in the 1990s that utilize dozens or even hundreds of electrodes with automated switching between electrode sets. From 24 to more than 100 metal electrodes are driven a short way into the ground along a line. Electric current is introduced into the earth by using two of these electrodes. Electric potential is then measured simultaneously between pairs of other electrodes. For an eight-channel system, one channel is used for the pair of current electrodes, and potential is measured simultaneously between pairs of potential electrodes on the remaining channels (up to seven at one time). Measurements between sets of electrodes are repeated in many combinations along the line of electrodes. The arrangement of electrodes (that is, where the current and potential electrodes are in relation to each other) and the distance between electrodes can vary depending on the electrode configuration used and the goal of the survey. Depth of investigation is increased by increasing the separation of the electrodes. Field crews consist of from two to four persons (figs. 8-10).

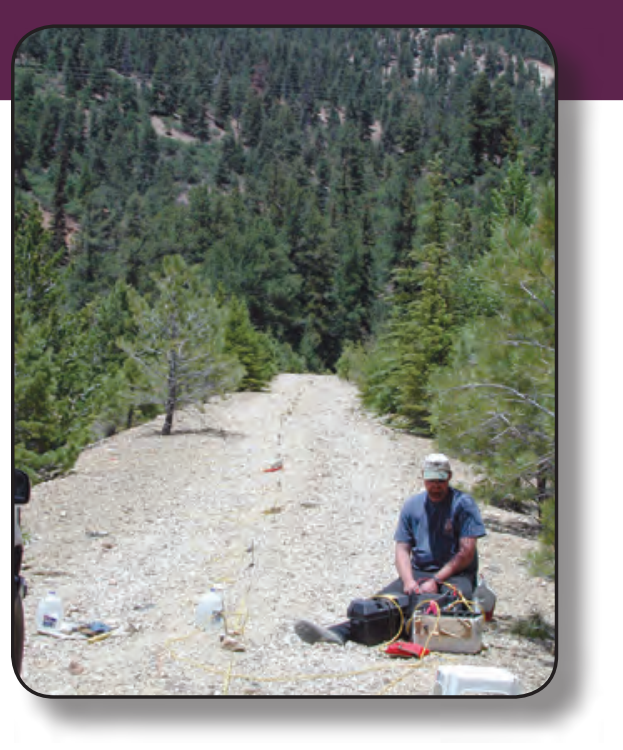

Around 1999, a capacitively coupled resistivity system was developed and marketed. This system does not use the metal-stake, or point, electrodes of the traditional resistivity system. Instead, pairs of insulated wire cables, called dipoles, are towed along the ground surface. Each cable in a dipole is called a line electrode. An alternating current is produced in the earth by the transmitter dipole, and voltage is measured simultaneously by several receiver dipoles. Variations of resistivity with depth can be determined by making multiple passes over the same area using different separations of the transmitter and receivers and different dipole lengths. Apparent resistivity and an earth resistivity model are determined in a standard manner (figs. 11-14).

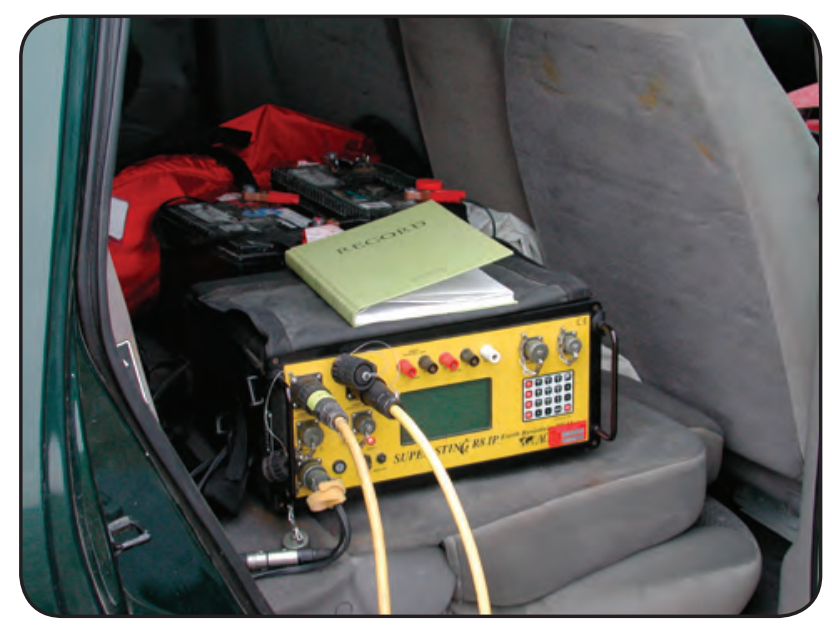

- Figure 8. A control unit for a multielectrode resistivity system. 
$\checkmark$ Figure 9. A metal stake and a "smart" electrode strapped to it for a multielectrode resistivity system.
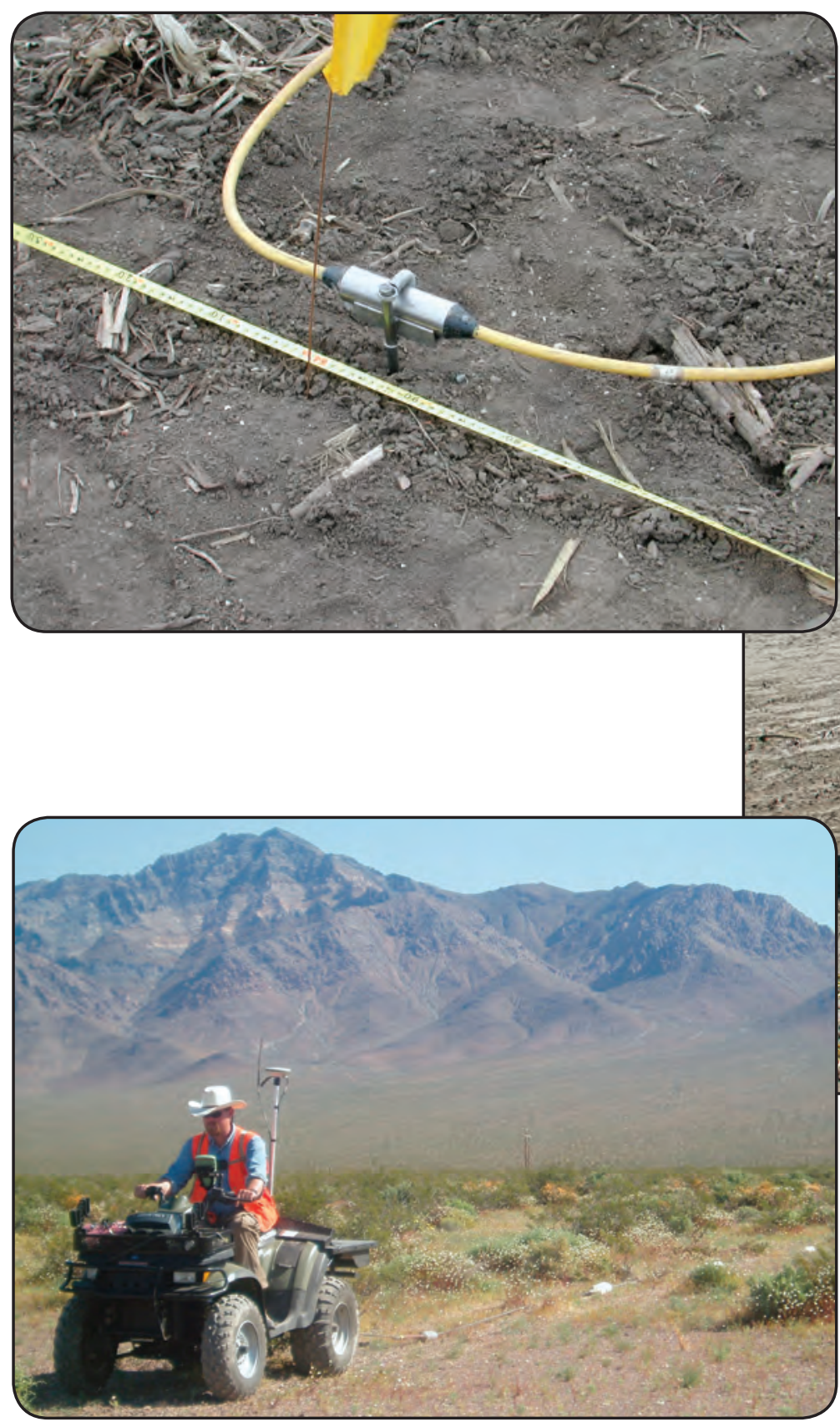

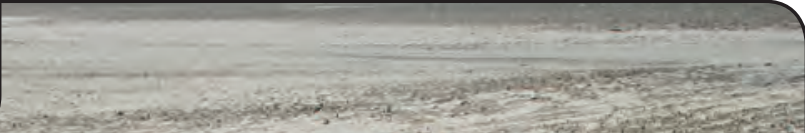

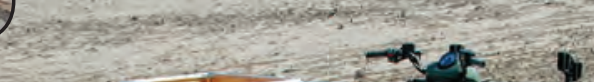




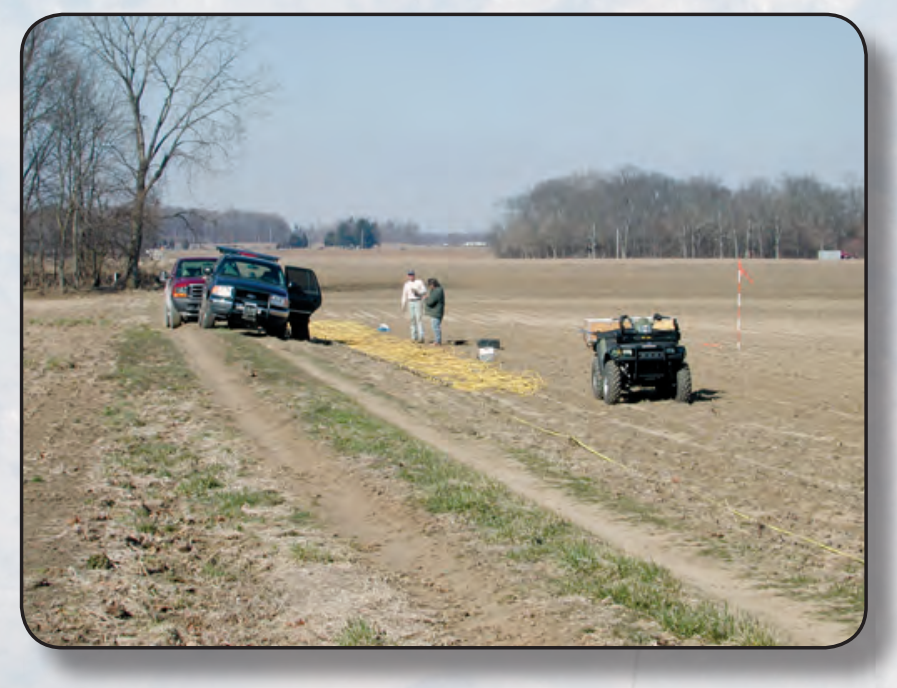

In some situations, the multielectrode resistivity method can be better suited to determine earth electrical layers than electromagnetic methods. By using multielectrode surveying with closely spaced electrodes, good resolution is achieved from a few meters' depth to 50-100 $\mathrm{m}$ depth. If a capacitively coupled system is used, exploration depth is limited to 10-20 meters. However, data collection with a capacitively coupled system is very fast and nearly continuous across the surface; tens of line-kilometers can be collected in a day when the system is towed by an all-terrain vehicle. Multielectrode surveys are the most efficient way to collect measurements and produce the most continuous and detailed geoelectric images of the subsurface.

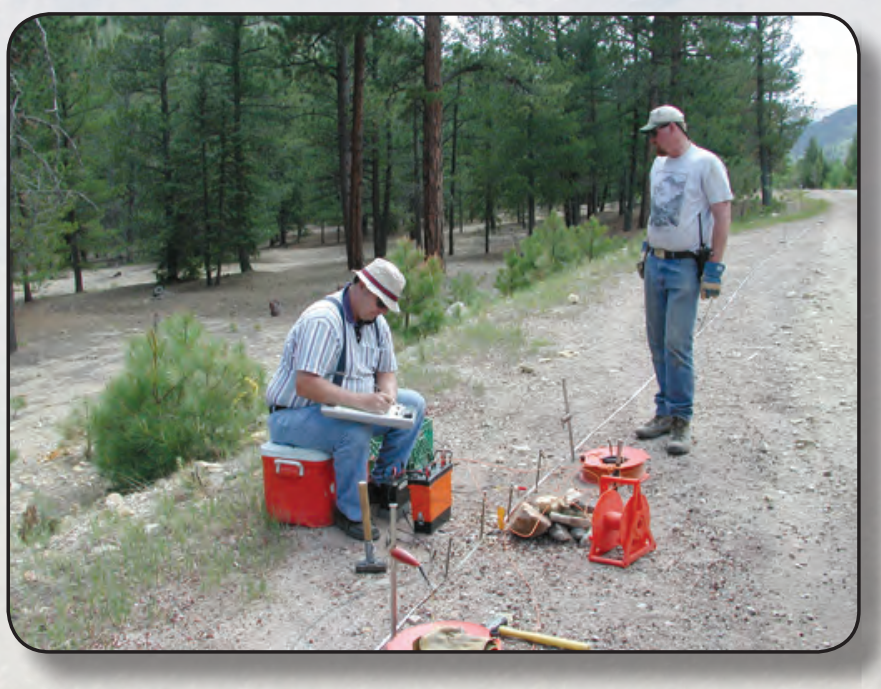

\section{Benefits}

With supportive geologic or borehole information, the resistivity method, in a favorable environment, can detect the contact between aggregate and bedrock, the presence of clay layers, and the water table.

The main benefits of the automated-switching resistivity method are listed:

- generally the least affected by cultural noise (of the methods discussed here),

- relatively quick site coverage; an experienced crew can collect 1 to 1.5 or more line-kilometers of data per day,

- quick data processing and interpretation; geoelectric sections are generated easily by using modeling software immediately after measurements are taken, and

- moderately low cost for equipment, data collection, and data modeling.

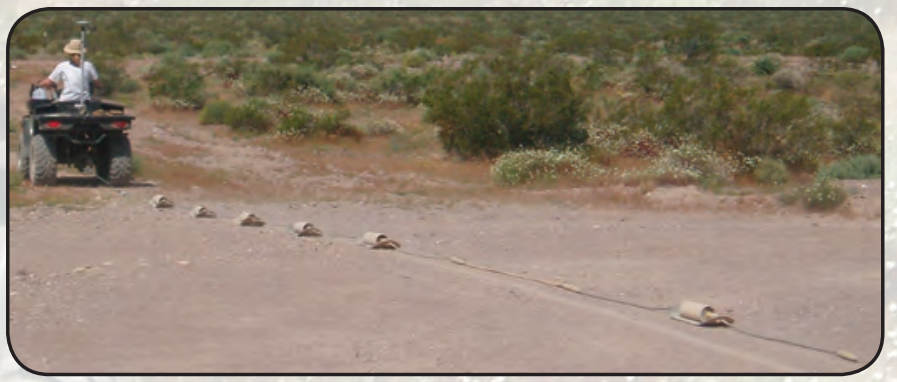

- Figure 12. Another view of a capacitively coupled resistivity system. The transmitter is the isolated, single cylindrical unit on a skid near the lower right of the picture. Closer to the all-terrain vehicle are five receivers. The wires on either side of each transmitter or receiver constitute a dipole antenna to induce or respond to, respectively, an alternating electric field in the earth. The separation between receivers and transmitter, as well as the dipole length, can be varied. 


\section{Limitations}

Different materials may have the same resistivity, so measurements alone should not be interpreted uniquely in terms of soil type or lithology. Supplementary geologic or geophysical information is required to differentiate between, for example, conductive clay and nonconductive sand that has conductive water occupying the pore space; or, as another example, between sand and gravel. There is also the problem of nonuniqueness or equivalence, in that various combinations of layer thickness and resistivity will be measured identically by the equipment.

Considerable distance may be required for an array of electrodes. Depending on the electrode separation and the sediment resistivity, the array length may be many times the depth to a target, such as bedrock.
There are many sources of noise that can affect the quality and accuracy of resistivity measurements, including:

- cultural features such as pipelines, buried utility cables, grounded power lines, and metal fences;

- lightning or natural earth (telluric) currents, which may induce voltage into the cables;

- lateral geologic variations, especially near-surface electrical variations; and

- leakage in the current wire.

Safety issues with electrical methods are limited to moving heavy cables, pounding stakes into the ground, electric current in the cables, and perhaps operation of all-terrain and other off-road vehicles. Other safety issues include the hazards of operation near roads and the danger of lightning strikes on the cables.

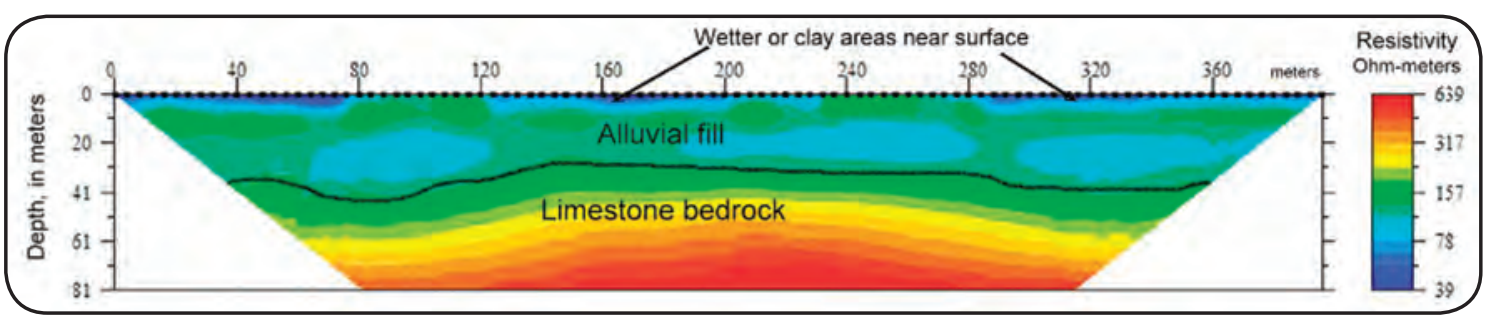

$\Delta$ Figure 13. Interpretation of a resistivity model from multielectrode resistivity data collected on alluvium on a flood plain. Limestone bedrock has electrical resistivity of about 150 ohm-meters and higher. The alluvium is mostly sand and gravel with clayey or sandy loam soil at the surface.

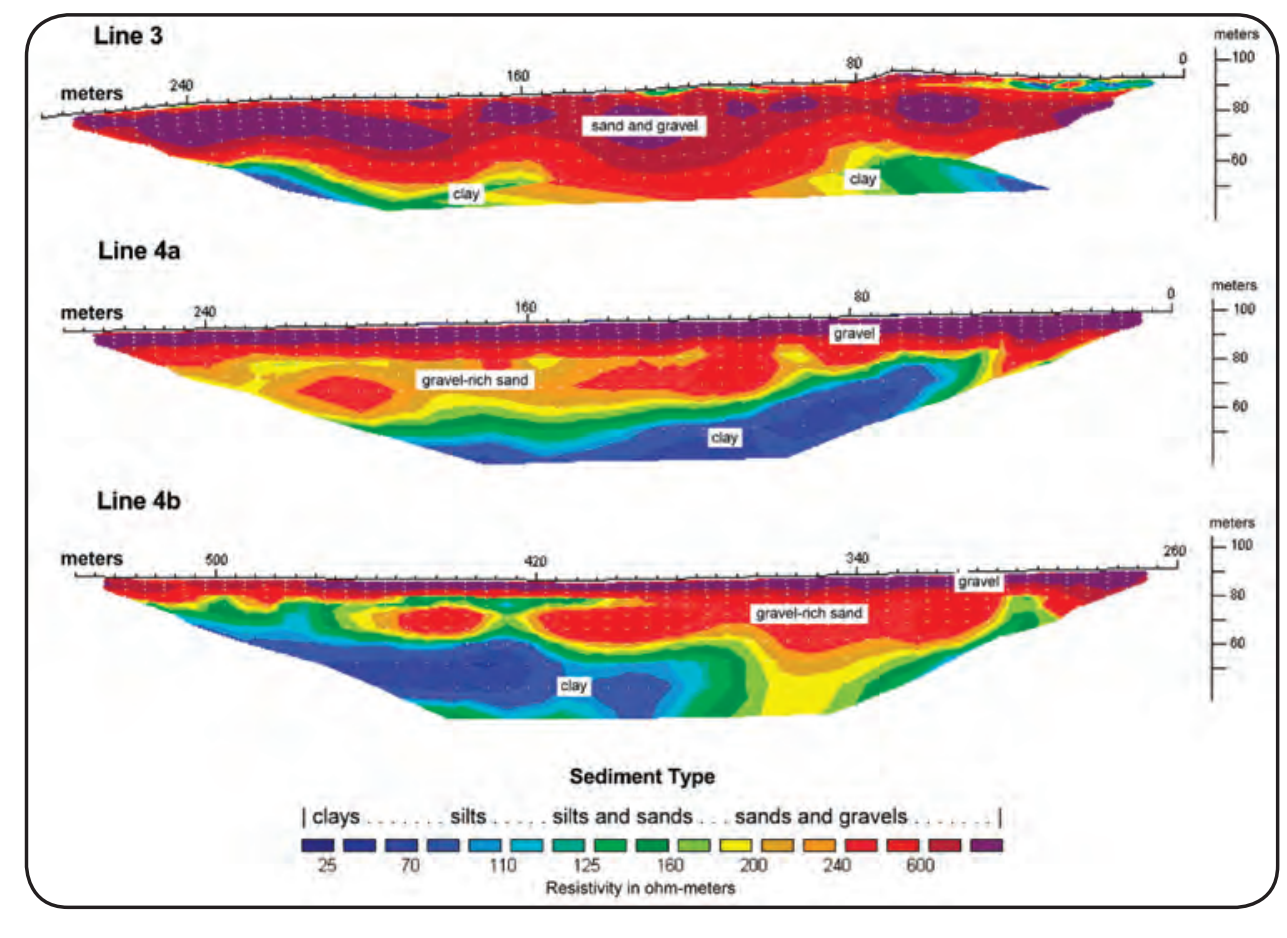

- Figure 14. Interpretations of resistivity models for multielectrode resistivity data collected over a sand and gravel deposit in a glacial outwash channel in Minnesota (adapted from Anderson, 2000). 


\section{Ground Penetrating Radar}

\section{Overview}

Ground penetrating radar (GPR) is a relatively new technique that was commercially developed in the 1970s for use in shallow earth exploration. GPR is an electromagnetic method that depends on the propagation of high-frequency $(10 \mathrm{MHz}$ to $3 \mathrm{GHz}$ ) electromagnetic (EM) energy in the ground. Because of this, the ground must have reasonably low conductivity, usually below $40 \mathrm{mS} / \mathrm{m}$ (or a resistivity above 25 ohm-meters).

A transmitting antenna radiates an electromagnetic wave into the ground. When the electromagnetic wave encounters a change in electromagnetic properties, some of the wave is reflected back toward the receiving antenna, where the amplitude of the electric field and arrival time are detected. As radar waves travel through the ground they lose amplitude due to spherical divergence (the energy is spread out over an increasingly larger sphere), intrinsic attenuation (the production of electric current by the electric field and the conversion of that current to heat), and scattering by heterogeneity.

The most common cause of reflections is a change in water content, which causes a change in bulk dielectric permittivity. Water content variations are associated with sedimentary structures, lithology, grain size, density (porosity), and saturation. Contrasts in electrical conductivity, from clay or metallic objects, also cause reflections.

Because of the high frequencies used, the GPR method has exceptional resolution of subsurface features, often much less than a meter. However, depth of investigation in sediments can be quite limited, with 15 to 20 meters the typical maximum depth in very low conductivity, nonfrozen materials, and less than a meter in conductive materials.

While GPR may not be commonly used to characterize sand and gravel deposits because of its limitations (discussed in the following "Benefits" section), there may be occasions that its higher resolution compared to other geophysical techniques may be useful at particular sites. Generally, when the environment is suitable (that is, where the surface and subsurface are relatively free of clay), GPR can be used to map the vertical and horizontal limits of sand and gravel to determine the volume of the deposit. It can be used also to detect the top of lenses of fine-grained (clayey) materials, to map stratigraphy within the sand and gravel, to determine the depth to water table, and to determine

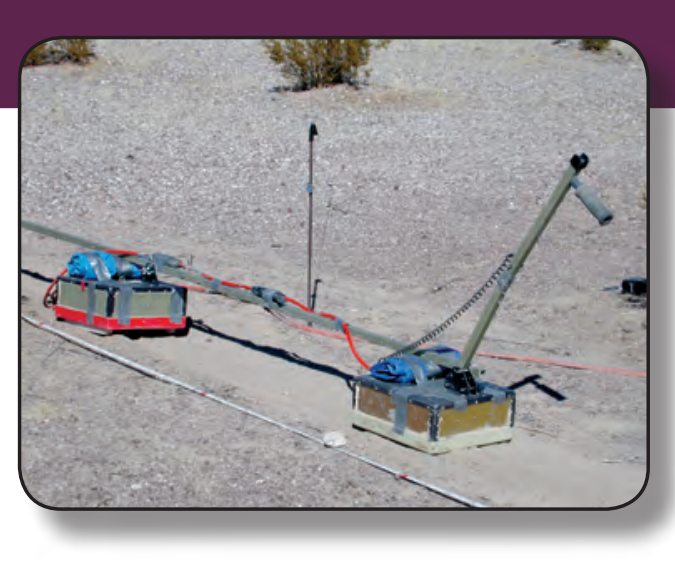

thickness of overburden. The GPR method usually cannot be used to differentiate sand from gravel unless there is additional geologic information.

Several commercial systems are available today that are relatively inexpensive to own or rent. The equipment is portable, rugged, and easy to operate, though a trained person is required to interpret the data. GPR equipment consists of one or two antennas, some cables, a power source, and a control device that also records data. The antennas commonly are mounted on a sled or in a cart and moved by hand or with an all-terrain or other small vehicle along a straight path on the ground. The control unit may be with the antennas or separated from them. The antennas come in different sizes, with larger antennas having lower frequencies. Lower frequency antennas have lower spatial resolution, typically 0.5 to $1.5 \mathrm{~m}$, but can detect deeper objects or layers. Depending on the equipment and antennas, a one- or two-person field crew is required (figs. 15-19).

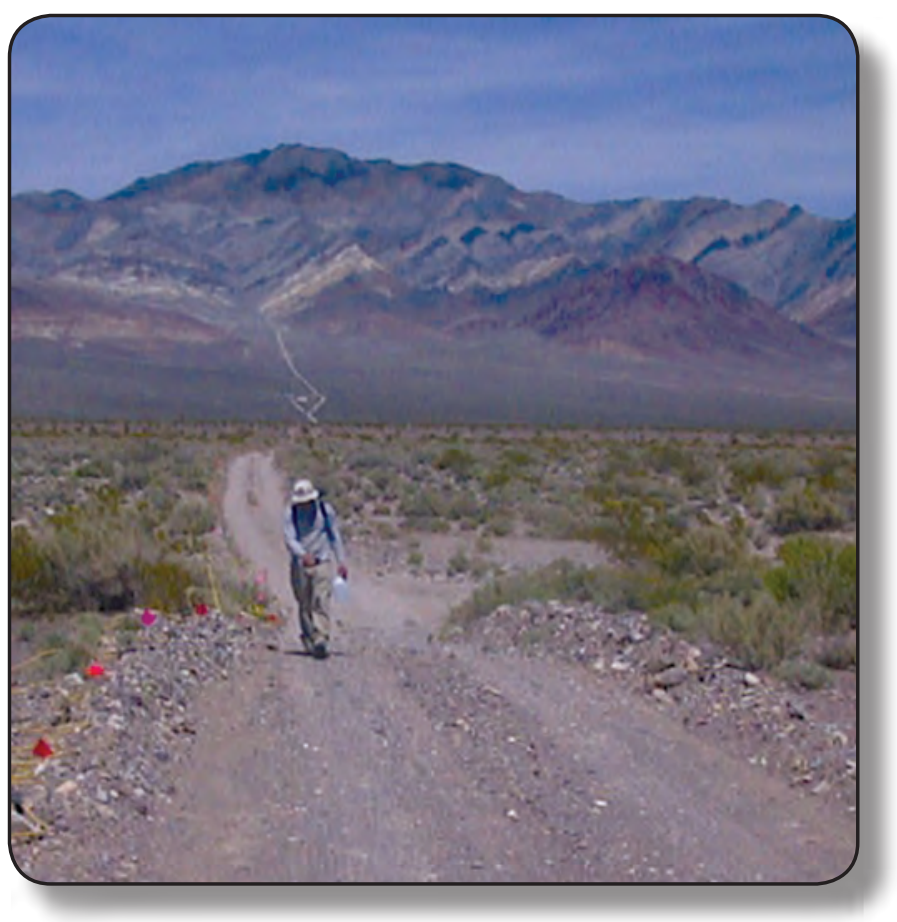




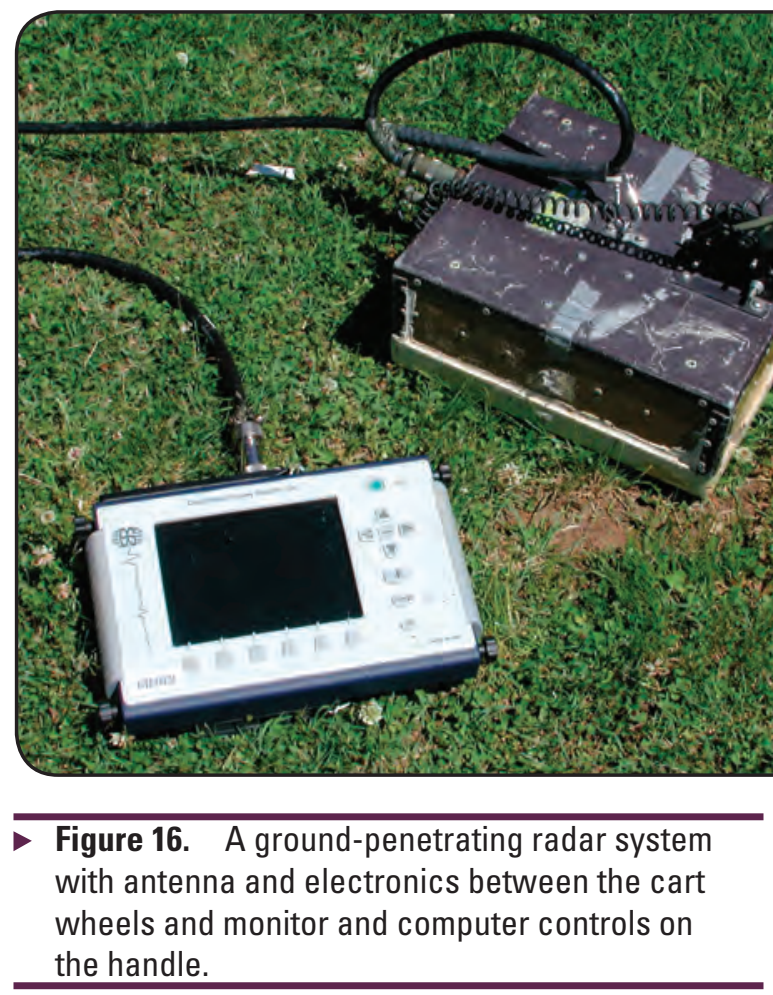

4 Figure 15. A ground-penetrating radar system with antenna separate from electronics and computer controls. This system can be mounted in a cart or towed by hand.

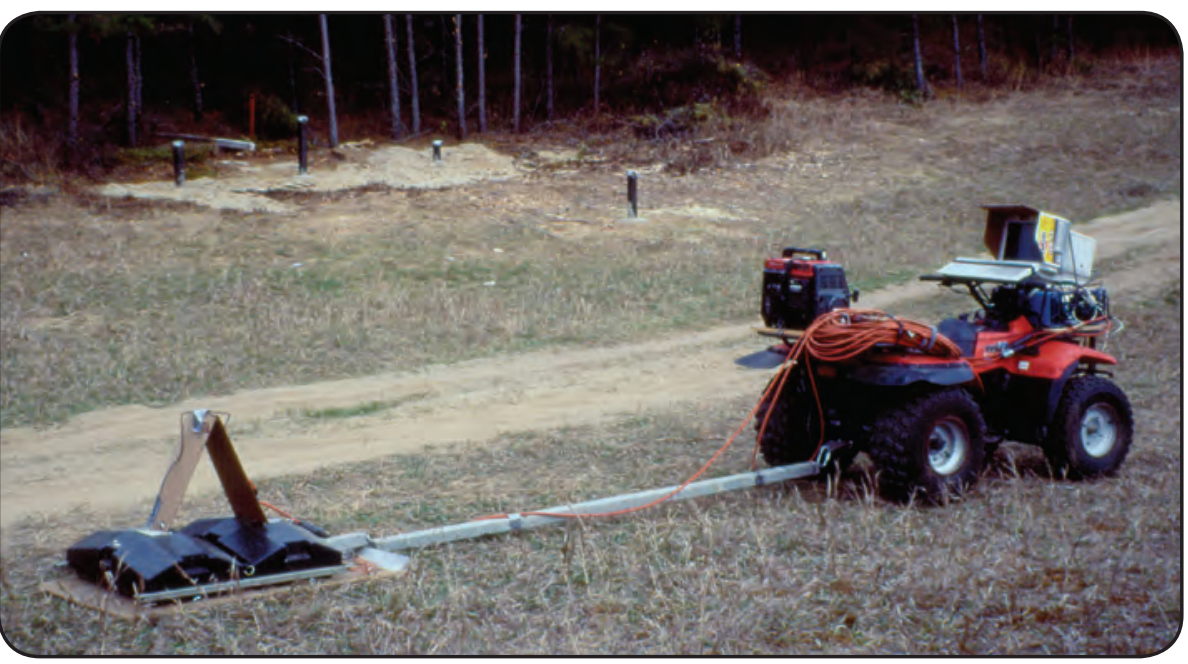

\ Figure 17. Ground-penetrating radar equipment mounted on an all-terrain vehicle with antennas towed behind. 
- Figure 18. A 17-antenna ground-penetrating radar system. Antennas are inside the yellow shell and are pushed by a tractor. This multiantenna system collects data across a 2-meter-wide swath, and data are processed into a 3-D volume. The position of the tractor is determined using an automated laser-tracking theodolite.

\section{Benefits}

Ground can be covered relatively quickly using GPR, resulting in detailed, near-continuous profiles (or vertical sections of data). Where profiles are near boreholes or other sources of stratigraphic information, the raw data images (if scaled correctly) can often be interpreted directly, providing almost realtime results during surveys. Collections of profiles can be used to produce three-dimensional blocks of data, from which horizontal or vertical slices of information can be extracted.

Over ground that has low conductivity and low scattering losses, surveys can potentially reach depths of 15 to $20 \mathrm{~m}$ when using low-frequency antennas. However, 3 to $6 \mathrm{~m}$ is more typical with midsized antennas. Compared to other geophysical techniques, GPR resolution is very good with decimeter-scale

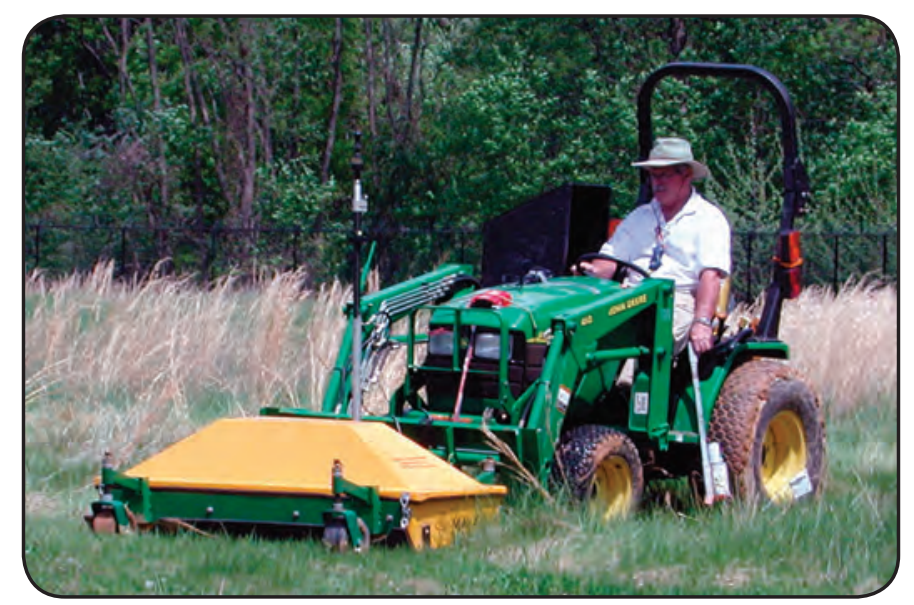

resolution of subsurface features using antennas with a frequency of $500 \mathrm{MHz}$ or higher. When antenna frequency is close to $100 \mathrm{MHz}$, resolution is at the meter scale.

In a favorable environment and with supportive geologic information, GPR often can detect a reflection from the top of bedrock and the water table. The tops of clay layers are usually detected, but the bottoms of the clay layers and reflectors below the clay cannot be detected. Voids and faults sometimes can be detected.

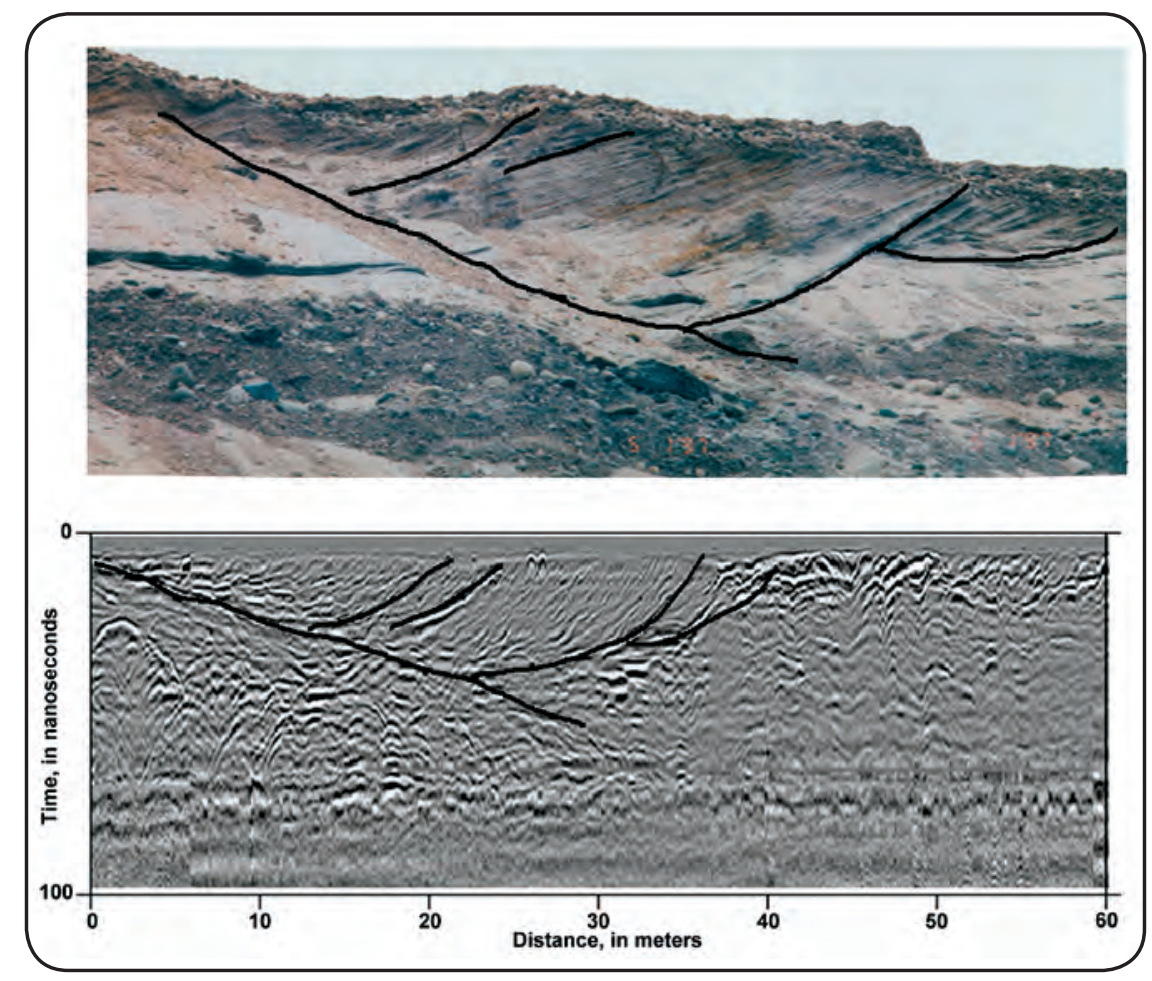

- Figure 19. Interpretation of ground-penetrating radar data (bottom image) collected near an active sand and gravel quarry (top image). Hyperbolicshaped reflections near the left side of the radar image are from large cobbles and boulders, similar to those seen in the lower left area of the upper image. 


\section{Limitations}

Success with the GPR method is site specific. Ground electrical conductivity is the major factor limiting the GPR depth of investigation. Survey depth may be extremely limited (much less than $1 \mathrm{~m}$ ) if ground conductivity is high (above 30 to $40 \mathrm{mS} / \mathrm{m}$ ). If the target area is covered with a clayey soil, the soil will have to be removed before GPR can be used effectively. If conductive layers or lenses occur within the deposit, GPR cannot "see" past them. Another factor limiting investigation depth is scattering of the radar wave energy due to large cobbles and boulders. This can be minimized with the use of lower-frequency antennas. Finally, for the limits of the deposit to be detected, there must be sufficient contrast in permittivity or conductivity between the sand and gravel and adjacent sediment or rock.
In order to focus the radar waves into the ground, the antenna must remain in close contact with the ground surface. Therefore, the terrain over which the survey is conducted cannot be too rough or contain numerous objects that must be avoided, such as trees, boulders, and fences. Because of the relatively high resolution, extra expense can be added if topographic surveys are required so that antenna locations are known.

Safety issues with GPR are relatively minor and are associated with typical cautions as applied to any field work. There may be some electric shock issues if the equipment is operated in the rain or wet environments. Other safety issues include the hazards of operating trucks and all-terrain vehicles off road.

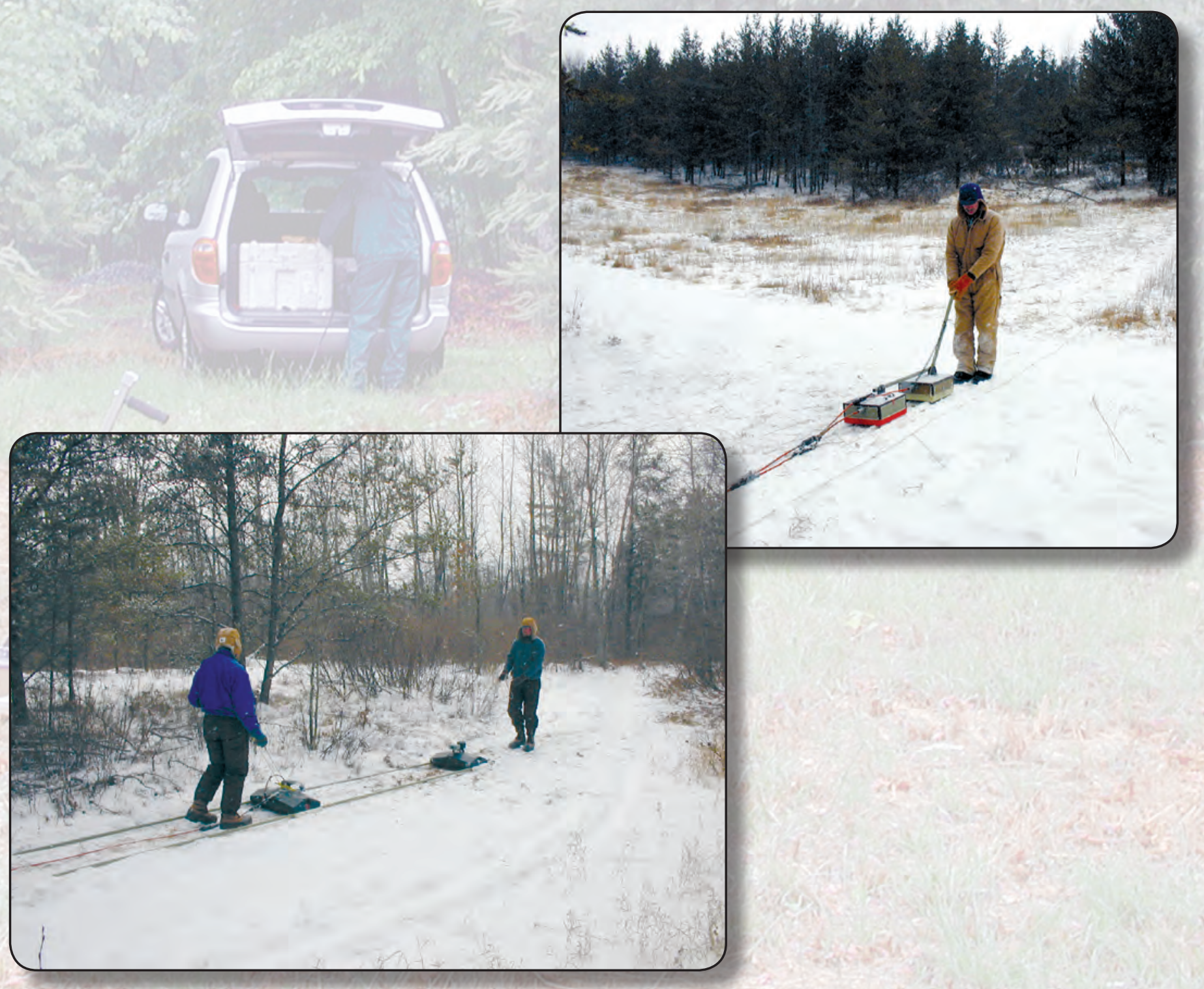




\section{Time-Domain Electromagnetic}

\section{Overview}

Time-domain electromagnetic (TDEM), also called transient electromagnetic or TEM, is a sounding method that determines the resistivity at different depths below the measurement station. It was developed in the 1920s and 1930s in Europe. Commercial equipment has been widely available since the 1960s and 1970s. It is a popular method in ground-water and environmental studies, mineral exploration, and geologic mapping. The application of TDEM for sand and gravel deposits is similar to that of DC resistivity.

Time-domain methods take one or more measurements as a function of time. The transmitter is an ungrounded, large, square or rectangular loop of insulated wire. A direct current is passed through the wire for a brief time, producing a magnetic field about the loop. The current is then abruptly stopped, and the decaying magnetic field induces electric current in the ground under the loop, roughly in the shape of the loop. This current diffuses into the ground, causing progressively larger and deeper loops of current, called eddy currents. As the current diffuses downward and outward into the ground, it produces a secondary magnetic field. The voltage produced in the receiver by these secondary magnetic fields is called a transient and can be interpreted with respect to the electrical resistivity structure of the ground. This voltage is measured at sequential time intervals, with later time intervals containing information from deeper layers. Because the transient response is measured over a very short time period, the measurements are repeated many times and an average determined to improve the signal. The maximum depth of exploration is one to two times the transmitter loop diameter. To determine lateral variations, both the transmitter and receiver are moved to new stations, which may be along a straight path or situated at various locations in the study area.

TDEM equipment is quite portable and easy to operate but moderately expensive. Two persons is the practical size for a TDEM survey crew. An experienced geophysicist uses computers and modeling to determine the variation of resistivity with depth from the field measurements (figs. 20-21).

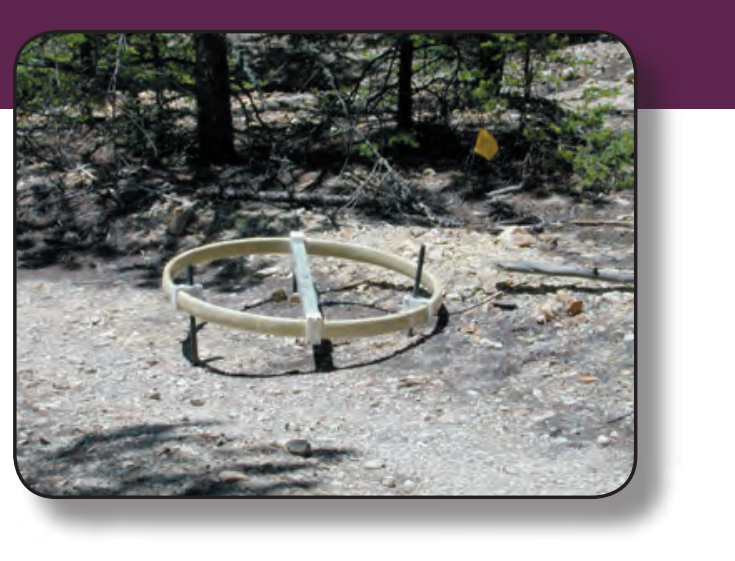

\section{Benefits}

In comparison to the DC resistivity sounding method, TDEM has the following advantages:

- faster data collection for deep soundings,

- more sensitive to small variations in conductivity,

- does not have contact resistance problems with very resistive surface layers,

- less sensitive to varying surface topography and to dipping layers, and

- better at detecting very conductive targets.

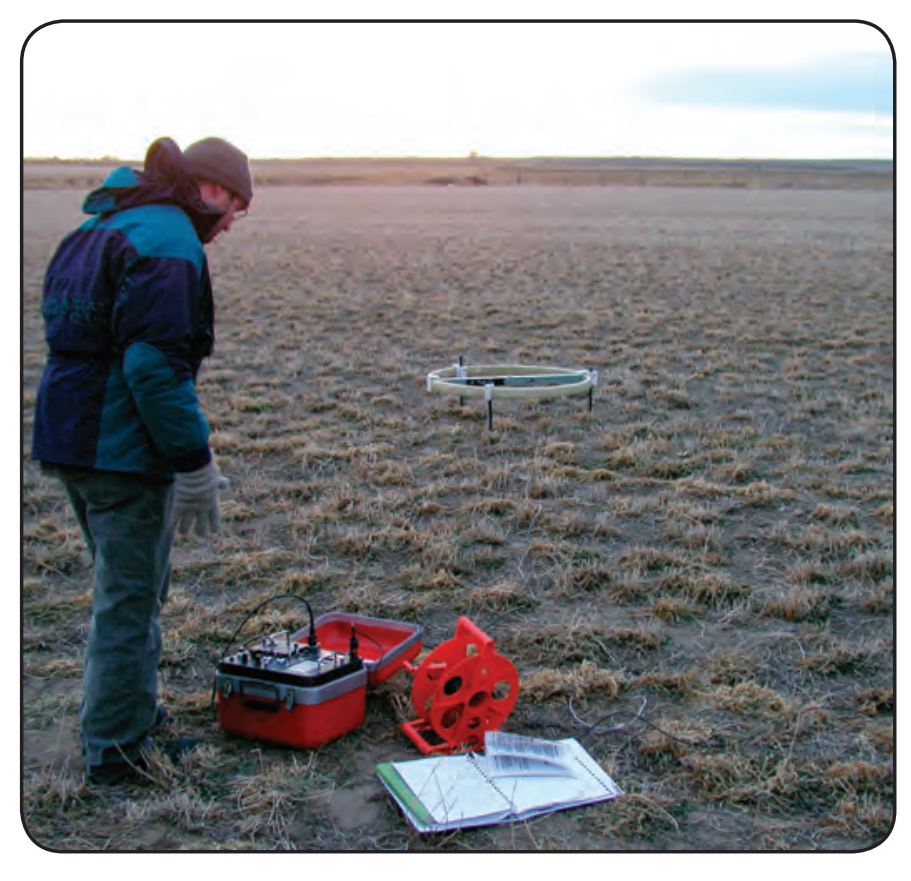

A Figure 20. Collecting time-domain electromagnetic data. The control unit is in the foreground. The receiver coil is in the background. A wire square transmitter loop, 40 meters on a side, surrounds the receiver coil. 


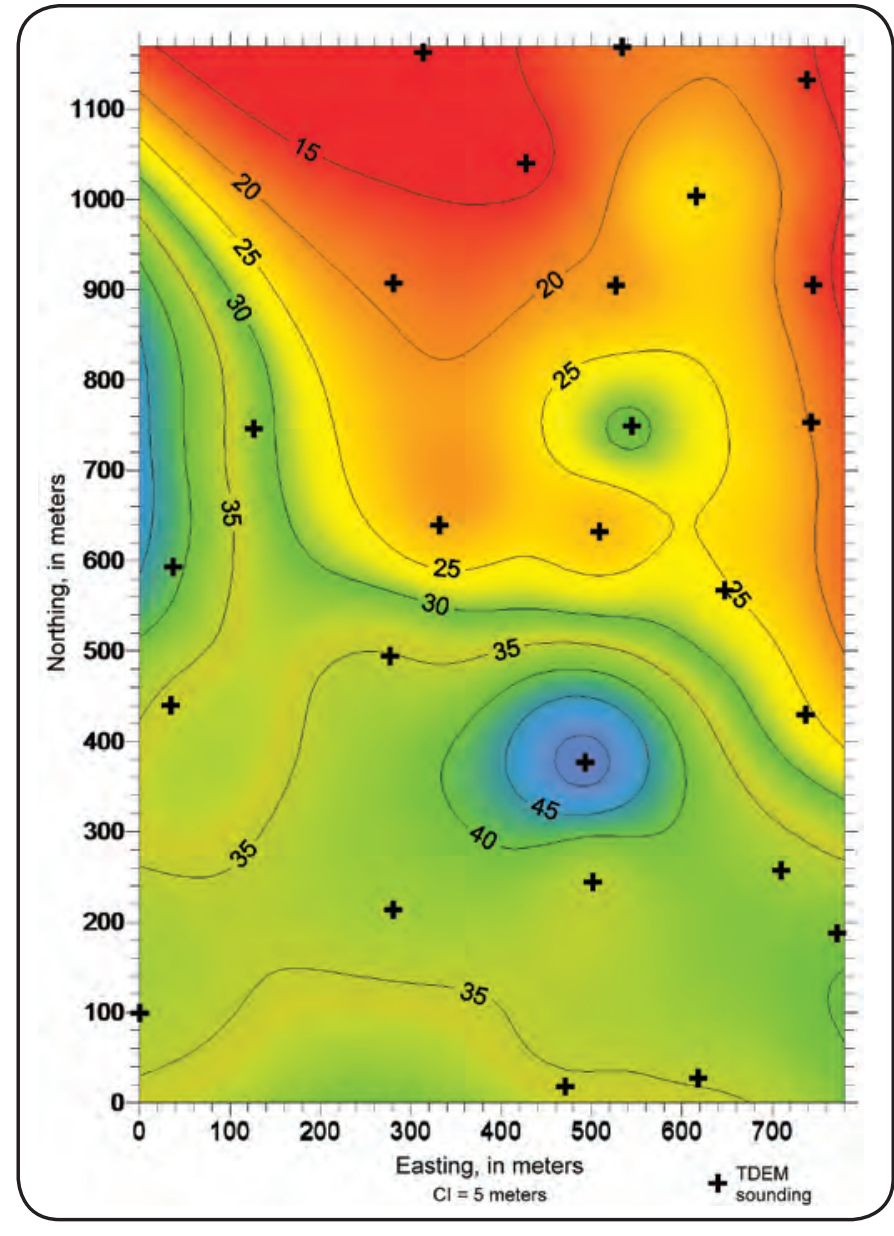

A Figure 21. Bedrock depth, in meters, determined using time-domain electromagnetic soundings on an alluvial flood plain.

In addition, DC resistivity requires larger electrode spacing for greater depths, while TDEM uses larger loop size and later time measurements. Direct current resistivity requires much larger electrode spacing as TDEM does for the same exploration depth.

With respect to the FDEM methods (see "FrequencyDomain Electromagnetic" section), TDEM has better layer resolution and definition. Because measurements are made after the transmitter is turned off, TDEM is generally insensitive to small coil misalignments. FDEM is very sensitive to coil misalignment because measurements are taken with transmitter turned on. Both methods usually can detect boundaries of the aggregate with bedrock or clay and sometimes can detect the water table.

\section{Limitations}

The TDEM method is poor at differentiating relatively resistive targets, such as the freshwater level in sand or gravel. However, it can detect conductive ground water (water containing large concentrations of dissolved solids). TDEM is also poor at resolving very shallow targets, generally those less than 10 meters deep.

Sources for noise in TDEM measurements include the following:

- $50-\mathrm{Hz}$ and $60-\mathrm{Hz}$ power lines;

- nearby radio and radar transmitters;

- thunderstorms;

- high wind, which may cause the receiver coil to vibrate in the Earth's magnetic field;

- metallic structures, including fences and power lines;

- buried metallic objects such as pipes and cables; and

- rarely, induced polarization from clayey soils.

Depending on loop size and sounding spacing, data collection can be relatively slow; generally, fewer than 10 soundings can be collected in a day. To speed up data collection, a two-person crew can lay out extra transmitter loops in advance of moving the transmitter and receiver units from loop to loop. Local, strong heterogeneity can be identified by placing the receiver at various places around the transmitter loop.

Safety issues with TDEM are minimal and are associated with typical cautions as applied to any field work. Caution must be taken to eliminate the possibility of lightning strikes on the wire loops. Other safety issues include the hazards of operating trucks and all-terrain vehicles off road. 


\section{Frequency-Domain Electromagnetic}

\section{Overview}

Like TDEM, frequency-domain electromagnetic (FDEM) methods were developed in the 1920s and 1930s in Europe. Commercial equipment has been widely available since the 1960s. FDEM instruments determine the electrical conductivity of earth materials at one or more frequencies. Here we are only interested in what are commonly referred to as ground conductivity meters or terrain conductivity meters, and not VLF (very low frequency) instruments or metal detectors. Ground conductivity meters may be more useful in the exploration stage for sand and gravel than in producing detailed characterization of a deposit. FDEM equipment is portable, relatively inexpensive, and easy to operate. Data are easy to interpret.

In general, a small transmitter coil is energized with an alternating current, which produces a time-varying primary magnetic field. The magnetic field penetrates into the earth and produces alternating electric currents (eddy currents) in conductive targets. These eddy currents produce secondary magnetic fields, which are sensed, along with the primary magnetic field, by a small receiver coil. The instrument calculates an apparent conductivity of the ground; this calculation depends upon the spacing and orientation of the coils, the frequency of the primary alternating current, and the ratio of the secondary to primary magnetic fields.

One person can perform surveys with the smaller conductivity meters, which contain transmitter and receiver coils in the same housing. Two persons are required for instruments where the coils can be separated; one person must hold each coil. The smallest meters can even be used on vertical faces of excavations (figs. 22-25).

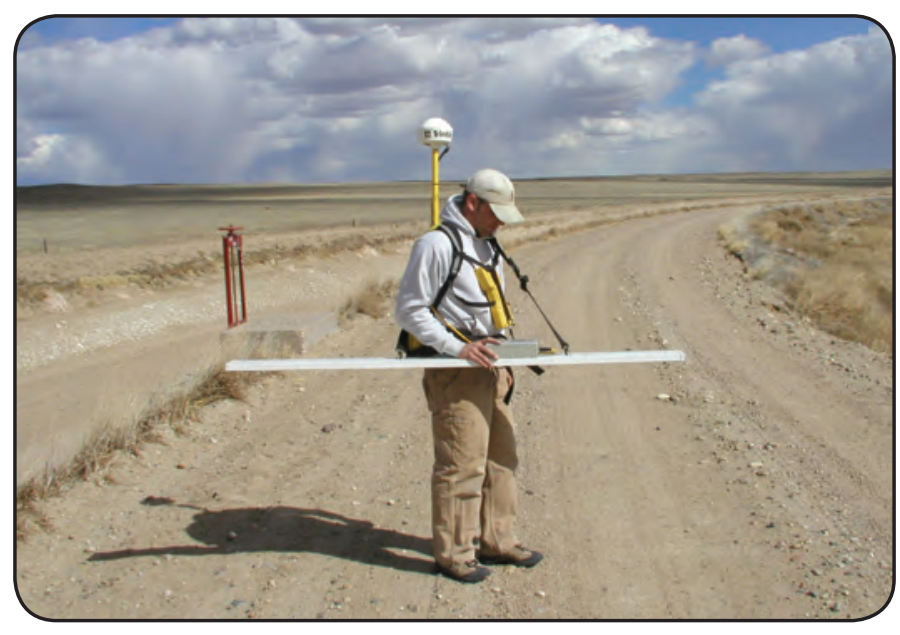

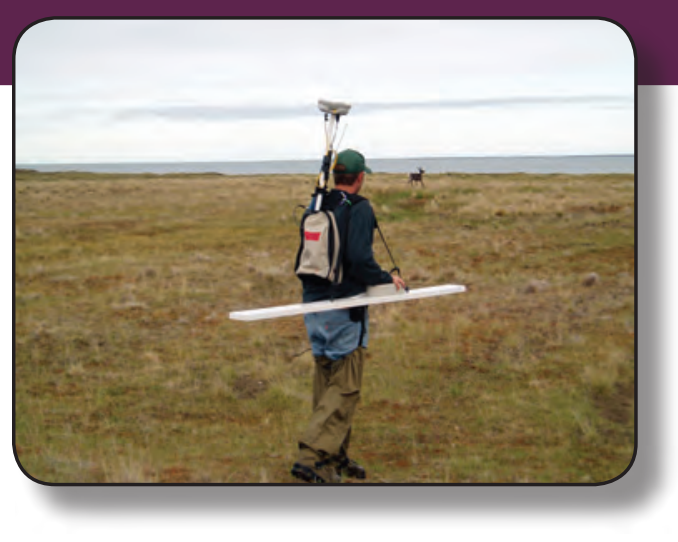

\section{Benefits}

This equipment is quite portable, relatively inexpensive, and easy to operate. Because contact with the ground is not required, data collection is rapid, and large areas can be covered quickly. Little or no data processing is required for preliminary interpretations, which can be made in the field. Site conductivity maps are made easily using the raw data. Large aerial surveys may indicate prospective sand and gravel deposits. Both the FDEM and TDEM methods can usually detect boundaries of the aggregate with bedrock or clay and sometimes can detect the water table.

\section{Limitations}

These instruments may not measure conductivity accurately in highly resistive ground. In highly conductive ground the calculated apparent conductivity may be substantially different from the true conductivity of the ground. Often, only qualitative vertical layering information can be obtained; quantitative information can be minimal. Sometimes modeling the data and using DC resistivity measurements to calibrate the data can improve interpretation.

Power lines, fences, and buried metallic pipes can produce noise in the data. Relative misalignment of the transmitter and receiver coils will introduce errors in the data.

Safety issues with FDEM are minimal and are associated with typical cautions as applied to any field work, including hazards of operating vehicles off road.

4 Figure 22. A frequency-domain conductivity meter. The meter has fixed coil spacing but measures several frequencies at once. A global positioning system antenna is on the operator's back to record station location. 


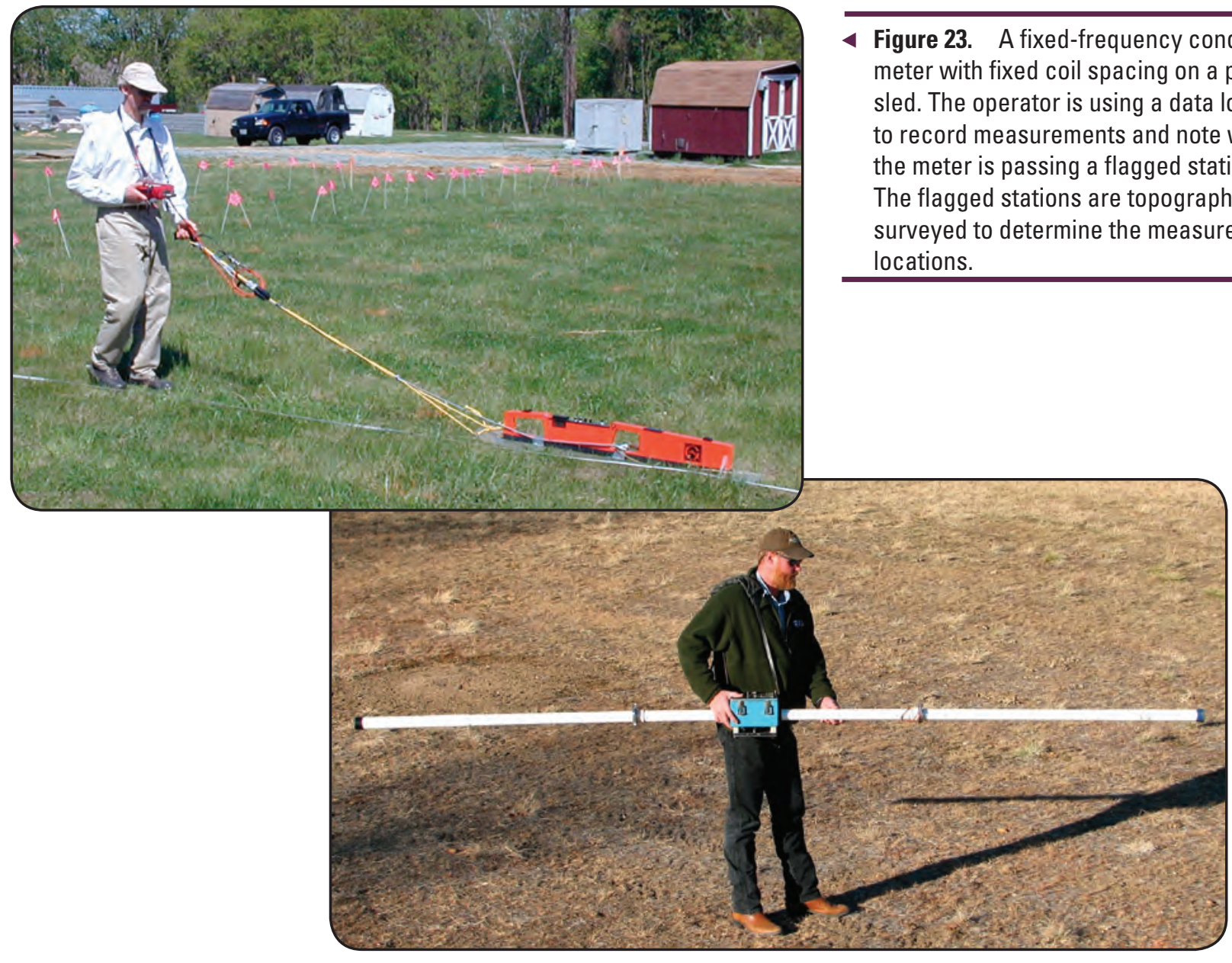

- Figure 24. A fixed-frequency conductivity meter with fixed coil spacing. A data logger can be attached to record readings.

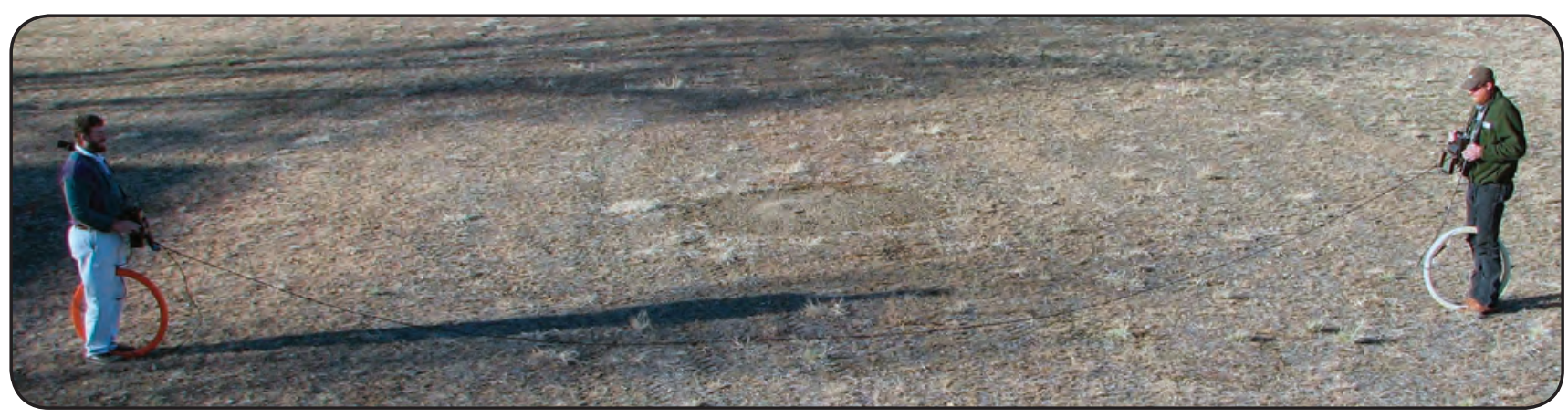

A Figure 25. A conductivity meter utilizing separate coils. 


\section{Summary and Conclusions}

When considering the use of geophysics to characterize sand and gravel deposits, the cost and efficiency of the various methods must be considered. It is beyond the scope of this report to tabulate and present all costs associated with conducting geophysical surveys. However, estimates for new equipment prices (year 2006), data-collection costs (in terms of number of field personnel and data-collection rates), and data-processing costs (in terms of processing and interpretation days for every datacollection day) can be made. These are presented in table 4 .

Seismic methods require a lot of field work with relatively expensive equipment, and the data cannot generally be interpreted immediately in the field. However, lateral boundaries and depth to bedrock can usually be determined. TDEM equipment is relatively expensive and data collection is relatively slow, but site coverage can be excellent and data can be quickly processed. FDEM methods are good for rapid data collection and identifying lateral changes in ground conductivity with relatively inexpensive equipment, but determining depths of layers can be problematic. GPR equipment is relatively inexpensive and data collection is rapid, but depth of investigation can be shallow. Even though the cost of multielectrode resistivity equipment is relatively high, especially for a 100-channel system, data collection is relatively quick and uncomplicated when compared to traditional 4-electrode surveys. However, setting up the electrodes and taking measurements (even though automated) can take hours. Initial data interpretation of lateral boundaries and layers can be performed by the field crew automatically and within minutes after a section is completed.

Safety issues and their costs also should be considered for each method. Some of these issues were mentioned in the previous sections devoted to each technique. However, we do not address all safety concerns associated with the field operations of the techniques.
The geophysical techniques discussed here allow for nearly continuous profiles of detailed information that provides continuity between sampling sites or boreholes. With resolution ranging from a few centimeters to many meters, depending on the technique and specific equipment used, geophysical surveys can provide information on the areal extent and thickness of deposits, overburden thickness, and depth to water table. However, resolution decreases with depth for all surface geophysical methods. In addition, estimates of layer thickness can be different from actual thickness because of uncertainties in the measurement process and model ambiguity. It is very important to calibrate measurements and interpretations using borehole and test-pit data to guarantee the most accurate interpretations. Interpretations are improved with advanced knowledge of local stratigraphy, hydrology, and cultural conditions.

Data collection over broad areas can be relatively quick, and equipment ownership or rental, maintenance, and deployment can be relatively inexpensive. The techniques generally are minimally invasive and do not damage the environment or property. Because of this, geophysical methods might be allowed where permission for drilling or excavation has been refused.

Because of their advantages, and despite their limitations, geophysical methods have proven to be useful supplements to traditional geologic mapping and sampling in the characterizing sand and gravel deposits and planning quarry development. Geophysical measurements can extend information beyond control points; support and augment ground-truth data from drill holes, pits, and laboratory measurements; and help to define or to revise the volume estimates (reserve and probable reserve calculations). In general, the geophysical methods discussed here are noninvasive, fast, and quiet.

Table 4. Comparison of approximate costs for selected geophysical methods. This does not include the cost of software for data processing and visualization, which can be hundreds of dollars to thousands of dollars.

\begin{tabular}{|c|l|c|c|c|}
\hline Method & \multicolumn{1}{|c|}{$\begin{array}{c}\text { Equipment (new) } \\
\text { in \$1,000 US }\end{array}$} & $\begin{array}{c}\text { Field } \\
\text { persons }\end{array}$ & $\begin{array}{c}\text { Data collection } \\
\text { per day }\end{array}$ & $\begin{array}{c}\text { Data-processing } \\
\text { days per field day }\end{array}$ \\
\hline Seismic & $\begin{array}{l}21-37(24 \text { geophones) } \\
40-75(48 \text { geophones) } \\
0.1 \text { (hammer source) } \\
10-20 \text { (powered source) }\end{array}$ & $2-4$ & $0.2-0.6$ line-kilometer & $\begin{array}{l}\text { Refraction: } 2-3 \\
\text { Reflection: many }\end{array}$ \\
\hline Resistivity & $\begin{array}{l}\text { about } 50 \text { (48 electrodes) } \\
\text { about } 80(100 \text { electrodes) }\end{array}$ & $2-4$ & $1-2$ line-kilometers & $0-1$ \\
\hline GPR & $25-40$ & $1-2$ & $1-5$ line-kilometers & $1-2$ \\
\hline TDEM & $45-65$ & 2 & $6-20$ soundings & $1-2$ \\
\hline FDEM & $20-30$ & $1-2$ & $1-5$ line-kilometers & $1-2$ \\
\hline
\end{tabular}




\section{References and Selected Additional Reading}

Anderson, H., 2000, Aggregate resource evaluation for a portion of Felton Prairie, Clay County, Minnesota: Minnesota Department of Natural Resources, Project 334-11, 82 p.

Auton, C.A., 1992, The utility of conductivity surveying and resistivity sounding in evaluating sand and gravel deposits and mapping drift sequences in northeast Scotland: Engineering Geology, v. 32, p. 11-28.

Beres, M., and Haeni, F.P., 1991, Application of groundpenetrating radar in hydrogeologic studies: Ground Water, v. 29 , p. $375-386$.

Bisdorf, R.J., 1985, Electrical techniques for engineering applications: Association of Engineering Geologists Bulletin, v. 22, p. 421-433.

Bolen, W.P., 2006, Sand and gravel, construction: U.S. Geological Survey Mineral Commodity Summaries, p. 142-143.

Boyd, T.M., 2003, Introduction to geophysical exploration: Golden, Colorado School of Mines online course [accessed February 28, 2007, at http://galitzin.mines.edu/INTROGP/].

Bristow, C.S., and Jol, H.M., 2003, Ground penetrating radar in sediments: Geological Society of London, Special Publication $211,330 \mathrm{p}$.

Burger, H.R., Sheehan, A.F., and Jones, C.H., 2006, Introduction to applied geophysics-Exploring the shallow subsurface: New York, Norton, 554 p.

Butler Dwain, ed., 2005, Near-surface geophysics: Tulsa, Okla., Society of Exploration Geophysicists, Investigations in Geophysics, no. 13, 732 p.

Davis, J.L., and Annan, A.P., 1989, Ground-penetrating radar for high-resolution mapping of soil and rock stratigraphy: Geophysical Prospecting, v. 37, p. 531-551.

Dunn, J.R., 1983, Aggregates-Sand and gravel, in Lefond, S.J., ed., Industrial minerals and rocks (5th ed.), v. 1: New York, American Institute of Mining, Metallurgical, and Petroleum Engineers (AIME), p. 97-108.

Dunn, J.R., 1991, Geology and exploration, in Barksdale, R.D., ed., The aggregate handbook: Washington, D.C., National Stone Association, p. 41-45.

Dunn, J.R., and Cutcliffe, W.E., 1971, Selecting aggregate deposits-A geologic view: Rock Products, v. 74, no. 3, p. 75-79.
Ellefsen, K.J., Lucius, J.E., and Fitterman, D.V., 1998, An evaluation of several geophysical methods for characterizing sand and gravel deposits: U.S. Geological Survey OpenFile Report 98-221, 26 p.

Ellefsen, K.J., Lucius, J.E., and Fitterman, D.V., 1999, Geophysics in exploration for sand and gravel, in Johnson, K.S., ed., Forum on the Geology of Industrial Minerals, 34 ${ }^{\text {th }}, 1998$ : Oklahoma Geological Survey Circular 102, p. 147-149.

Ellefsen, K.J., Tuttle, G.J., Williams, J.M., and Lucius, J.E., 2005, S-wave refraction survey of alluvial aggregate: U.S. Geological Survey Scientific Investigations Report 2005-5012, 14 p.

Federal Lands Highway Program, 2004a, Application of geophysical methods to highway related problems - Surface geophysical methods: Federal Highway Administration, Online Solution Matrix [accessed February 28, 2007, at http://www.cflhd.gov/agm/solutionMatrix/index.htm].

Federal Lands Highway Program, 2004b, Engineering applications-Subsurface characterization, Locating shallow sand and gravel deposits: Federal Highway Administration, Online Solution Matrix [accessed February 28, 2007, at http://www.cflhd.gov/agm/solutionMatrix/index.htm].

Fisher, T.G., Jol, H.M., and Smith, D.G., 1995, Ground penetrating radar used to assess aggregate in catastrophic flood deposits, N.E. Alberta, Canada: Canadian Geotechnical Journal, v. 32, p. 817-879.

Geometrics, Inc., 2001, OhmMapper TR1 Operation Manual: San Jose, Calif., Geometrics, Inc., 147 p. [accessed February 28, 2007, at ftp://geom.geometrics.com/pub/ GeoElectric/Manuals/].

Goldman, H.B., 1994, Sand and gravel, in Carr, D.D., ed., Industrial minerals and rocks, 6th ed.: Littleton, Colo., Society for Mining, Metallurgy, and Exploration, Inc., p. 869-877.

Goldman, H.B., and Reining, D., 1983, Sand and gravel, in Lefond, S.J., ed., Industrial minerals and rocks, 5th ed., v. 2: NewYork, American Institute of Mining, Metallurgical, and Petroleum Engineers (AIME), p. 1151-1166.

Jacobson, R.P., 1955, Geophysical case history of a commercial gravel deposit: Mining Engineering, v. 7, p. 158-162. 
Jol, H.M., Parry, D., and Smith, D.G., 1998, Ground penetrating radar-Applications in sand and gravel exploration, in Bobrowsky, P.T., ed., Aggregate resources-A global perspective: Rotterdam, Netherlands, A.A. Balkema, Inc., p. 295-306.

Knepper, D.H., Jr., Langer, W.H., and Miller, S., 1995, A survey of natural aggregate properties and characteristics important in remote sensing and airborne geophysics: Nonrenewable Resources, v. 4, p. 99-120.

Langer, W.H., 1988, Natural aggregates of the conterminous United States: U.S. Geological Survey Bulletin 1594, 33 p., 2 plates, scale 1:5,000,000.

Langer, W.H., 2006, Construction sand and gravel, in Kogel, J.E., Trivedi, N.C., Barker, J.M., and Krukowski, S.T., eds., Industrial minerals and rocks, 7th ed.: Littleton, Colo., Society for Mining, Metallurgy, and Exploration, Inc., p. 159-169.

Langer, W.H., Drew, L.J., and Sachs, J.S., 2004, Aggregate and the environment: Alexandria, Va., American Geological Institute, $64 \mathrm{p}$.

Langer, W.H., and Glanzman, V.M., 1993, Natural aggregate-Building America's future: U.S. Geological Survey Circular 1110, 39 p.

Langer, W.H., and Knepper, D.H., Jr., 1998, Geologic characterization of natural aggregate-A field geologist's guide to natural aggregate resource assessment, in Bobrowsky, P.T., ed., Aggregate resources-A global perspective: Rotterdam, Netherlands, A.A. Balkema, Inc., p. 275-293.

Lenhart, W.B., 1960, Sand and gravel, in Gillson, J.L., ed., Industrial minerals and rocks, $3 \mathrm{~d}$ ed.: New York, The American Institute of Mining, Metallurgical, and Petroleum Engineers (AIME), p. 733-758.

Loke, M.H., 1999, Electrical imaging surveys for environmental and engineering studies-A practical guide to 2-D and 3-D surveys: Geometrics, Inc. [accessed February 28, 2007, at ftp://geom.geometrics.com/pub/GeoElectric/Literature/ Lokenote.pdf].

Lucius, J.E., Olhoeft, G.R., Hill, P.L., and Duke, S.K., 1992, Properties and hazards of 108 selected substances, 1992 ed.: U.S. Geological Survey Open-File Report 92-527, 554 p.

McCuaig, S.J., and Ricketts, M.J., 2004, Ground-penetrating radar-A tool for delineating aggregate-resource deposits: Newfoundland and Labrador Department of Mines and Energy, St. John's, Newfoundland, Geological Survey Report 04-1, p. 107-115.

McNeill, J.D., 1980, Electromagnetic terrain conductivity measurement at low induction numbers: Mississauga, Ontario, Geonics, Ltd., Technical Note TN-6, 15 p.

Nabighian, M.N., ed., 1991, Electromagnetic methods in applied geophysics, v. 2, Applications, parts A and B: Tulsa, Okla., Society of Exploration Geophysicists, Investigations in Geophysics, no. 3, 972 p.
Odum, J.K., and Miller, C.H., 1988, Geomorphic, seismic, and geotechnical evaluation of sand and gravel deposits in the Sheridan, Wyoming, area: U.S. Geological Survey Bulletin 1845, 32 p.

Patterson, S.B., 1937, Crushed and broken stone, chapter 42, in Industrial minerals and rocks: New York, American Institute of Mining and Metallurgical Engineers, p. 795-836.

Reynolds, J.M., 1997, An introduction to applied and environmental geophysics: Chichester, England, Wiley, 796 p.

Saarenketo, T., and Maijala, P., 1994, Applications of geophysical methods to sand, gravel, and hard rock aggregate prospecting in northern Finland, in Luttig, G.W., ed., Aggregates-Raw materials giant: Report on the $2 \mathrm{~d}$ International Aggregates Symposium, Erlangen, Germany, October 2227, 1990, p. 109-123.

Sharma, P.V., 1997, Environmental and engineering geophysics: Cambridge, England, Cambridge University Press, $475 \mathrm{p}$.

Sheriff, R.E., 1991, Encyclopedic dictionary of exploration geophysics, 3d ed.: Tulsa, Okla., Society of Exploration Geophysicists, 376 p.

Telford, W.M., Geldart, L.P., and Sheriff, R.E., 1990, Applied geophysics, 2d ed.: Cambridge, England, Cambridge University Press, 790 p.

Tepordei, V.V., 2006, Stone, crushed: U.S. Geological Survey Mineral Commodity Summaries, p. 158-159.

Thoenen, J.R., 1932, Prospecting and exploration for sand and gravel: U.S. Bureau of Mines Information Circular 6668, 259 p.

Timmons, B.J., 1994a, Prospecting for natural aggregates-An update, part 1: Rock Products, v. 97, no. 8, p. 43-45.

Timmons, B.J., 1994b, Prospecting for natural aggregates-An update, part 2: Rock Products, v. 97, no. 9, p. 23-25.

Timmons, B.J., 1994c, Prospecting for natural aggregates-An update, part 3: Rock Products, v. 97, no. 10, p. 43-46 and 54.

Timmons, B.J., 1995, Prospecting for natural aggregates-An update: Rock Products, v. 98, p. 31-37.

U.S. Army Corps of Engineers, 1995, Geophysical exploration for engineering and environmental investigations: Engineer Manual EM 1110-1-1802, USACE CECW-EG, multiple pagination [accessed February 28, 2007, at http://www.usace.army.mil/inet/usace-docs/eng-manuals/ em.htm].

Wilcox, S.W., 1944, Sand and gravel prospecting by the earthresistivity method: Geophysics, v. 9, p. 36-46. 


\section{Glossary}

Definitions have been adapted from Sheriff (1991), Lucius and others (1992), Reynolds (1997), http://en.wikipedia.org/ and other general sources.

A

alternating current Alternating current is an electric current where magnitude and direction of the current changes (reverses) cyclically over time. Alternating current always produces an alternating magnetic field. There will be an associated alternating electric field in nearby conductors. Alternating current is commonly used in houses and offices. See also direct current.

apparent conductivity Apparent conductivity is the electrical conductivity of homogeneous ground that will produce the same response as was measured in the field at a single set of measurement parameters. For a frequency-domain electromagnetic instrument, measurement parameters might include excitation frequency, coil geometry, and intercoil separation. An apparent conductivity can be defined for each set of these parameters. The actual ground conductivity may be very different from the apparent conductivity. This is due in part because the conductivity of earth materials can change both laterally and vertically. However, a single measurement from a conductivity meter cannot discern these variations. By collecting measurements at different frequencies and(or) different coil separations, and by understanding the construction and limitations of the meter, an electrical conductivity model of the earth can be constructed beneath a measurement station.

apparent resistivity Apparent resistivity is the electrical resistivity of homogeneous ground that will produce the same response as was measured in the field using a single set of measurement parameters. Apparent resistivity and apparent conductivity are the reciprocal of each other. Apparent resistivity allows comparison of measurements from one area to another and provides a first approximation to the actual earth resistivity. Modeling is required to determine the representative electrical resistivity structure of the earth.
C

conduction current Conduction current is an electric current produced by an applied voltage difference or an electric field.

\section{D}

density Density is mass per unit volume. Common measurement units are gram per cubic centimeter $\left(\mathrm{g} / \mathrm{cm}^{3}\right)$, kilogram per cubic meter $\left(\mathrm{kg} / \mathrm{m}^{3}\right)$, pound per cubic foot $\left(\mathrm{lb} / \mathrm{ft}^{3}\right)$, and ton per cubic yard (ton/yd $\left.\mathrm{d}^{3}\right)$. For two objects of the same size, the denser one will weigh more or feel heavier. Density of sand and gravel is in the range of 1.7 to $2.3 \mathrm{~g} / \mathrm{cm}^{3}$; for sandstone 1.6 to $2.7 \mathrm{~g} / \mathrm{cm}^{3}$; for shale, 1.75 to $3.2 \mathrm{~g} / \mathrm{cm}^{3}$; and for limestone, 1.9 to $2.9 \mathrm{~g} / \mathrm{cm}^{3}$.

dielectric permittivity Dielectric permittivity (also called dielectric constant) is a measure of a material's ability to store electric energy by separating opposite polarity charges in space when an external electric field is applied. It is measured in farad per meter $(\mathrm{F} / \mathrm{m})$. Often, relative dielectric permittivity (RDP) is used to describe this property. RDP is the ratio of a material's dielectric permittivity to the dielectric permittivity of free space (like in outer space), which is $8.854 \times 10^{-12} \mathrm{~F} / \mathrm{m}$. RDP is unitless. Air has an RDP of about 1.003. The $\mathrm{RDP}$ of water is about 80 , depending on temperature. The RDP of common dry earth materials is often between 2 and 6 . However, when water is present in the material, the dielectric permittivity usually increases as water content increases. A mixture of relatively dry sand and gravel has an RDP between 3 and 6 . The RDP of saturated sand and gravel is usually between 16 and 36, depending on porosity. The speed of radar waves (or any electromagnetic wave) in a material is determined mostly by the RDP. Radar waves (and light waves) travel faster in air and slower in water. If a material has a very low RDP, it is called a dielectric or an insulator.

diffusion Diffusion is a physical process where matter (particles) or energy is spontaneous spread from high concentration to 
low concentration. In geophysics, it can refer to the transport of an electric field or magnetic field, or to the movement of charges in response to an applied electric or magnetic field. Diffusion causes rapid, exponential decay of the electric and magnetic field with distance and time. See also propagation, which is a different physical process.

Direct current Direct current is an electric current where the flow of electric charge (such as electrons or ions) through a conductor is in one direction from high to low electric potential. Direct current always produces a magnetic field. Direct current is sometimes called galvanic current. Direct current is commonly used to run certain types of equipment and is commonly produced by batteries. See also alternating current.

\section{E}

elastic, elasticity Elastic means that an object returns to its original shape after having been deformed by an external force. An object that does not return to its original form is called plastic. Elasticity is defined by the various combinations of stress, strain, and the type of force being applied. The stress-strain properties of elastic earth materials are described by elastic moduli. The velocities of seismic waves can be expressed in terms of elastic moduli and density. See elastic properties.

elastic properties Elastic properties of an isotropic material (where the properties are the same measured in any direction) are described using three elastic moduli, one constant, and one ratio of strain. The bulk modulus $(k)$ is the stress-strain ratio under uniform (same in all directions) pressure or compression, $\Delta \mathrm{P} /(\Delta \mathrm{V} / \mathrm{V})$, that is, the change in pressure divided by the fractional change in volume. The bulk modulus is also called the modulus of compression. The shear modulus $(\mu)$ is the stress-strain ratio for simple shear, $(\Delta \mathrm{F} / \mathrm{A}) /(\Delta \mathrm{L} / \mathrm{L})$, that is, the change in force per unit area divided by the fractional change in length. The shear modulus is also known as the rigidity modulus. Young's modulus (E) is a measure of the stiffness of a material and is the stress-strain ratio when a rod is pulled or compressed, $(\Delta \mathrm{F} / \mathrm{A}) /(\Delta \mathrm{L} / \mathrm{L})$. Lamé's constant equals $(\mathrm{k}-2 \mu / 3)$. Poisson's ratio is the ratio of transverse strain to longitudinal strain. For example, when a rod is compressed, its length is shortened (longitudinal strain) and its width is increased (transverse strain). The velocity of $\mathrm{P}$-waves and $\mathrm{S}$-waves can be defined in terms of the bulk and shear moduli and the density. See also stress, strain, and elasticity.

electric current Electric current is the movement of electrically charged particles, such as electrons or ions. Electric current produces a magnetic field. Because electrical charge is involved there is also an electric field. The unit for current is the amp. See also alternating current, direct current, electrical methods, and electromagnetic methods.

electric field An electric field is produced by the presence of electrical charge, such as an electron or ion. An electric field contains electrical energy. An electric field can be static (strength does not change over time) or varying (strength changes over time). Common units for an electric field are volt per meter or Newton per coulomb.

electric potential Electric potential is the stored energy (or potential energy) per unit electric charge associated with a static (or constant) electric field. It is measured in volts. Electrical potential (or voltage) is only physically meaningful when measured between two different locations.

electrical conductivity Electrical conductivity is the ability of a material to conduct electric current and is the reciprocal of electrical resistivity. Units are siemens per meter $(\mathrm{S} / \mathrm{m})$. Electrical conductivity affects the attenuation of electromagnetic fields. Where electrical conductivity is near zero, such as in air (about $10^{-13} \mathrm{~S} / \mathrm{m}$ ), electromagnetic (EM) waves can travel great distances, but electric current generally cannot flow. In the earth, where electrical conductivity is often greater than 0.01 to 0.1 Siemen per meter, EM waves propagate relatively short distances, but electric current flows readily.

electrical methods Electrical methods measure electric potential (voltage) produced by electric current, or electric charge flow, in the ground. Current in earth materials is controlled by the fundamental material property called electrical conductivity (the 
ease with which electrical charge can be caused to flow) or its reciprocal, electrical resistivity. Because most dry rocks and sediments are poor conductors of electricity, conductivity is generally determined by the quality and quantity of water in the pore space, the connectedness of the pores, and the relative abundance of clay minerals. Electric conduction in conductive rocks and sediments principally occurs in two ways: electrolytic (or ionic), such as the movement of ions in water, and electronic (or ohmic), such as the movement of charge carriers (for example, electrons) in metals or clays. A third form of limited conduction, called displacement or dielectric conduction, occurs in media with low conductivity.

As electrical current passes through conductive ground it always produces both a magnetic field and an electric field. These fields can cause electrical polarization. The four common forms of electrical polarization include electronic (net displacement of the electron cloud with respect to the nucleus of an atom), ionic (displacement of charged atoms or molecules with respect to each other), orientational (aligning of molecules with asymmetrical charge distributions, like water molecules), and interfacial (local accumulations of migrating charge against a chemical or electrical barrier). The electrical methods focus on the electric field and sometimes on polarizations produced by charge flow.

Electrical methods include direct current resistivity, self potential (also called spontaneous potential), induced polarization, and seismoelectric.

electrical resistivity Electrical resistivity is that property of a material that resists the flow of electric current. Resistance converts electrical energy into heat, leading to a loss of electric potential or electric current. Electrical resistivity is the ratio of the electric field intensity between two parallel surfaces of a cube to the electric current density perpendicular to the same two surfaces. Resistivity is commonly expressed in ohm-meters (short for ohm-meter ${ }^{2}$ per meter). The resistivity of earth material covers a broad range. In general, soil, clay, and shale have low resistivity; sand and gravel have high resistivity; and limestone and some igneous rocks can have even higher resistivity. However, the amount and type of water in the material can drastically affect a material's bulk resistivity.

electromagnetic field An electromagnetic (EM) field is composed of two related fields, the electric field and the magnetic field. Typically, the strength of the two fields changes over time, alternating in strength in a cyclic and synchronized manner. A changing electric field produces a changing magnetic field, and the reverse. The number of cycles per second is called the frequency (usually measured in hertz $[\mathrm{Hz}]$, which is one cycle per second). Electromagnetic properties affect the propagation (or transmission) and attenuation of EM fields. An EM field cannot propagate for any great distance in conductive media like typical rocks and sediments because the electric field leads to electric current (also called conduction current) and rapid dissipation of the energy into heat. When an EM field occurs in media with low conductivity, such as air, ice, or resistive sediments, it travels or propagates as an electromagnetic wave; a radio wave is a common example.

electromagnetic methods The electromagnetic (EM) methods are the most complex and varied in terms of technique and equipment. EM methods involve alternating electric and magnetic fields with frequencies from about $10^{-5} \mathrm{~Hz}$ to about $10^{10} \mathrm{~Hz}$. When an EM field occurs in media with low conductivity, such as air, ice, or resistive sediments, it travels or propagates as a wave; a radio wave is a common example. Generally, below about $100 \mathrm{kHz}$ in conductive media, EM energy transport is governed by a diffusion process and conduction currents dominate. Above about $10 \mathrm{MHz}, \mathrm{EM}$ propagation in resistive media is governed by a wave process. With the exception of ground penetrating radar (GPR), which operates at frequencies from $10 \mathrm{MHz}$ to $4 \mathrm{GHz}$ ), EM methods generally work best over moderately conductive ground.

The EM methods differ from the electrical methods in that the electromagnetic fields in the ground are produced from electric or magnetic fields generated above the ground. Through a process called inductive coupling, which does not require direct contact of the transmitting source with the ground, currents are caused to flow in the ground. This can be 
an advantage over the electrical methods that require electrodes inserted into the ground (called galvanic coupling) by allowing much quicker surveying over an area. EM methods often measure the magnetic field and(or) the electric field, making the equipment, and sometimes the interpretation, more complicated.

Some EM methods are passive in that the equipment used does not have to produce the field that interacts with the subsurface. These include the telluric, magnetotelluric, and VLF (very low frequency) methods. The frequency-domain EM, time-domain EM, and GPR methods are active-source methods that use a transmitter to produce an EM field. Transmitters usually consist of a large single loop of wire (often configured as a square), a small coil of wire with many turns, or a dipole (a straight length of wire or sheet of metal), through which is passed an alternating electric current or a pulse of current.

Alternating current in a loop of wire produces an alternating magnetic field, which induces current flow in nearby conductors. These induced currents, in turn, produce a secondary magnetic field. Alternating current in a dipole produces an alternating electric field, which then produces an alternating magnetic field that induces current flow in the earth. In either case, whether using an electrically shorted loop or an open dipole, alternating EM fields are produced in the earth. For the receiver using a loop, the secondary magnetic fields produce current flow in the receiver loop and a measurable voltage. For a receiver using a dipole, the secondary electric fields produce a voltage that is measured.

electromagnetic properties Electromagnetic properties affect the propagation and attenuation of electromagnetic fields in the earth. The three properties are electrical conductivity, dielectric permittivity, and magnetic permeability. The speed of EM waves is determined mostly by dielectric permittivity. The attenuation (or reduction in strength) of EM waves is determined mostly by electrical conductivity.

electromagnetic wave An electromagnetic wave is an electromagnetic disturbance (in this case an electromagnetic field) that propagates (moves or travels) in a periodically repeating manner, transferring energy from one place to another. Radiation (nonionizing) is a term synonymous with electromagnetic wave. The directions of the magnetic field and electric field are at right angles to each other and perpendicular to the direction of energy flow. Consider this cross shape: + . The electric field varies in strength (or amplitude) on the horizontal bar with positive amplitude to the right. The amplitude of the magnetic field changes on the vertical bar, with positive amplitude to the top. The direction of propagation then is out of and perpendicular to this page.

energy Energy is the capacity to do work. All physical systems possess this fundamental quantity. Energy is defined as the amount of work required to change the state of a system from one position or level to another position or level.

equivalence Equivalence means that a layer can produce nearly the same geophysical response for a variety of combinations of thickness and property magnitude. This is particularly true with the electrical, electromagnetic, and potential-field methods. For example, nearly the same electric current flows in two different resistive layers if the product of their thickness and resistivity are similar. Equivalence issues may be overcome using additional geologic or geophysical information. Equivalence is less of a problem with wave-based methods such as ground penetrating radar and seismic methods.

\section{I}

inversion Inversion is the process of determining a model, or distribution, of earth properties that reproduces the observed field. The model or distribution may not be unique.

isotope Isotopes are different forms of the same element that have different atomic weights; that is, the number of protons in the atom is the same, but the number of neutrons is different. Unstable isotopes decay, releasing radioactivity, until they form stable isotopes of either the same element or a different one.

\section{M}

magnetic field A magnetic field is the effect produced by moving electric charges (called an electric current). It is also called magnetic 
intensity, magnetic induction, or magnetic flux density. A magnetic field contains magnetic energy. Unlike electric fields, magnetic fields have no related "magnetic charges." A magnetic field that changes in strength over time produces an electric current in nearby conductors. The unit of magnetic field strength is either the tesla or gauss.

magnetic permeability Magnetic permeability is a measure of the degree to which a substance may be magnetized. It is the unitless ratio of the magnetic field strength to the external magnetizing force. Magnetic field strength is also called magnetic field, magnetic intensity, magnetic induction, or magnetic flux density. Magnetic field strength is equal to the magnetic permeability times the magnetizing force. Magnetic permeability affects electromagnetic fields in much the same way as electrical conductivity does.

magnetic susceptibility Magnetic susceptibility is a measure of the degree to which a substance may be magnetized. It is the unitless ratio of magnetization of a material to the external magnetizing force. Magnetization is also referred to as magnetic dipole moment per unit volume, magnetic polarization, or magnetization intensity. Magnetization is equal to the magnetic susceptibility times the magnetizing force. Most common earth materials are called diamagnetic; that is, their magnetic susceptibility is slightly negative and so produces a very small magnetic dipole moment (or strength) in a direction opposite to the inducing magnetizing force. Paramagnetic materials have a very small positive susceptibility and produce a magnetic dipole moment that slightly strengthens the magnetizing force. Examples of paramagnetic materials include the elements aluminum, calcium, platinum, sodium, uranium, and oxygen. A third class of materials is called ferromagnetic and has a positive and relatively large susceptibility. Iron, magnetite, and most steels are ferromagnetic.

model, modeling With respect to geophysical interpretation, a model is a conceptual representation of the distribution of physical properties in the earth that reproduce field geophysical measurements. However, agreement between the actual field data and the computed data from a model does not prove or validate the model. Models usually lack uniqueness and typically are simplifications of the actual distribution of properties in the earth. A model is used to provide a better understanding of the field observations. Modeling is the process of developing a model.

\section{$\mathbf{P}$}

P-wave A P-wave is an elastic body seismic wave. Particle motion is in the same direction as propagation. A P-wave is also called a primary wave, compressional wave, longitudinal wave, pressure wave, dilatational wave, rarefaction wave, or irrotational wave. P-waves travel faster than $\mathrm{S}$-waves in the same material.

potential field methods Potential field methods measure the Earth's gravitational or magnetic fields and the effects of local objects and structures on those fields. These are natural source or passive methods in that the equipment does not produce the field that interacts with the subsurface.

The gravity method measures variations of the Earth's gravitational field. These variations occur because of the density distribution of local masses (such as hills, valleys, and lakes) as well as deep geologic structure and even the position of the Moon with respect to the Earth. The average value of acceleration due to gravity at the Earth's surface is $980 \mathrm{~cm} / \mathrm{s}^{2}$ (about $32.15 \mathrm{ft} / \mathrm{s}^{2}$ ) or $980 \mathrm{gal}$. The microgravity method is precise enough to measure variations as small as several microgal $\left(10^{-6} \mathrm{gal}\right)$. Unconsolidated sediments such as sand, gravel, silt, clay, and soil have similar densities. The various types of rocks are usually slightly denser than sediments. The microgravity method might detect variations of the bedrock surface elevation, cavities in rock, or lateral changes between sediments or fill and rock. Gravimeters that are sensitive at the microgal level are relatively expensive and require a skilled and patient operator. The gravimeter measurement station, as well as local land and cultural masses, must be precisely located with a topographic survey, increasing the cost and time of gravity surveys. The processing and interpretation of gravity data require a skilled technician or scientist and computer software. For these 
reasons, microgravity is not considered in this report as a practical method for characterizing most sand and gravel deposits. On the other hand, the microgravity method could be considered in areas where electrical, electromagnetic, and seismic methods fail due to electrical or acoustic noise or cultural features such as buried or overhead utilities.

The geomagnetic method measures variations in the Earth's magnetic field, either its total intensity or the intensity of one or more individual components (such as vertical or horizontal). Variations of the magnetic susceptibility of sediments and rocks perturb this field. Ferrous metal objects cause the strongest perturbations. The Earth's magnetic field also varies in time, in position on the Earth (due to the dipole nature), and from magnetic storms. Magnetometers of high quality are relatively inexpensive, and their operation is easy to learn. Skilled technicians or scientists and computer software may be required for processing and interpretation. Geomagnetism is often used on a small scale to detect buried metal objects and on a large scale for regional geologic mapping. Generally, there will be insufficient contrast in magnetic susceptibility of sand and gravel compared to fines or clay and most sedimentary rocks to differentiate them. If bedrock has a strong susceptibility compared to the fill or overburden, then the geomagnetic method may be able to determine variations in depth to bedrock. Nevertheless, the geomagnetic method is considered here as an impractical method for characterizing most sand and gravel deposits.

propagation, propagate Propagation, in geophysics, refers to the movement of energy through a material. Seismic propagation implies the periodic and directional variation of elastic disturbance to transfer strain energy from place to place through wave motion. Electromagnetic propagation transfers electromagnetic energy from place to place by either wave motion or diffusion. The dominant energy transmission process depends upon the conductivity of the material, the excitation frequency, and a scale factor. At higher frequencies, wave propagation dominates, while at lower frequencies diffusion dominates. See also diffusion.

\section{$\mathbf{R}$}

radar wave A radar wave is an electromagnetic wave. Most ground penetrating radar antennas radiate a single pulse of an electromagnetic field. This field is called a radar wave as it propagates (or moves) away from the antenna. When the radar wave encounters a change in electromagnetic properties, part of the wave may be reflected off the boundary and part may continue through the boundary.

radioactivity, radiation Radioactivity is the emission of particles or energy as part of the decay of isotopes into isotopes of the same or different element. This ionizing radiation is typically alpha particles (equivalent to a helium nucleus: two protons and two neutrons), beta particles (actually electrons), and gamma rays (high energy electromagnetic waves like X-rays).

radioactivity methods Radioactive methods make use of the radioactive decay of certain elements. During the decay process, radiation is emitted. This radiation is typically alpha particles, beta particles, and gamma rays. Geiger counters detect alpha and beta particles. Scintillation meters detect gamma rays and beta particles.

Though there are many naturally occurring radioactive elements, only uranium, thorium, and potassium-40 are important in surface radioactivity detection methods (Telford and others, 1990). Radioactive elements, potassium in particular, tend to accumulate in clay and shale. If a sand and gravel deposit is bounded by shale or clay, a borehole radioactive method such as natural gamma logging might be useful for characterizing its thickness. This method typically is not recommended for characterization of typical sand and gravel deposits.

relative dielectric permittivity See dielectric permittivity.

rippability Rippability is a measure of the ability to excavate earth or rock materials with conventional excavating equipment. A material may be classified as nonrippable, marginally rippable, or rippable.

\section{S}

S-wave An S-wave is an elastic body seismic wave. Particle motion is in a direction perpendicular to the direction of propagation. 
An S-wave is also called a secondary wave, shear wave, transverse wave, rotational wave, distortional wave, equivolumnar wave, or tangential wave. S-waves can be polarized (the direction of particle motion) in the vertical (SV-wave) or horizontal (SH-wave) direction.

seismic methods Seismic methods depend on the transmission of strain energy (called seismic energy) as a wave through a medium. Strain occurs because of an external force being applied to a medium. The ratio of that force to the area it is applied to is called stress. If a body returns to its original shape after being subjected to stress, it is said to be elastic. A seismic source produces compression and(or) shear force in the ground. That force creates seismic wave energy that propagates from the source in all directions, in both the ground and the air.

The two main types of seismic waves are body waves, which travel through layers and objects, and surface waves, which travel in the interface between layers, such as at the Earth's surface. For this report, we discuss only body waves. The two types of body waves are P-waves and S-waves. In a particular medium, P-waves travel faster than $S$-waves. The velocity of these waves is determined by both the elastic properties and density of the ground. Seismic waves travel slower in unconsolidated sediments and faster in rock. Seismic wave detectors are called geophones, which convert ground vibrations (or motion) into a voltage response that is recorded by seismographs and computers.

seismic speed Seismic speed is a measure of how fast seismic waves travel (or propagate) in the ground without regard to the direction of that propagation. The speed of these waves is affected by both the elasticity, or stiffness, and density of the ground.

seismic velocity Seismic velocity is a measure of how fast seismic waves travel (or propagate) in the ground and the direction of that propagation. See also seismic speed.

seismic wave A seismic wave is an elastic disturbance that propagates from one place to another. Seismic waves are waves of elastic strain energy traveling through the ground. There are many types of seismic waves: (1) two types of body waves: $\underline{\text { P-waves }}$ and $\underline{\mathrm{S} \text {-waves; }}$ (2) several types of boundary or surface waves: Rayleigh waves, pseudoRayleigh waves (called ground roll), Love waves, Stonely waves, and tube waves;

(3) channel waves; (4) air waves (or shock waves); and (5) standing or stationary waves. this report, we are concerned only with $\mathrm{P}$-waves and $\mathrm{S}$-waves. See also elasticity.

The propagation of seismic waves is a complicated phenomenon. Seismic wave energy is a form of mechanic energy (particle motion). When the seismic wave encounters changes in elastic properties and(or) density, some of the energy is transmitted through the boundary and some is reflected back to the surface where it is measured as ground motion by geophones. The actual transmission and reflection of seismic waves is complicated and is often accompanied by transformation from one type of wave to another. As the waves travel through the ground, they lose energy due to spherical divergence (the energy is spread out over an increasingly larger sphere), intrinsic attenuation (absorption of elastic energy by the ground), and scattering (propagation to and away from the geophones). See also seismic methods.

strain Strain is the ratio of a change in length (or volume) of a medium or object to the original length (or volume) due to an external force, or stress. Strain is written as $\Delta \mathrm{L} / \mathrm{L}$ or $\Delta \mathrm{V} / \mathrm{V}$, where $\Delta$ means "change in."

stress Stress is the ratio of force to the area to which it is applied (written as F/A). Pressure is an example, with units of pound-force per square inch. A normal force is applied perpendicular to a surface and tends to compress an object or material. A tangential force (or shear force) is applied parallel to a surface and tends to shear the object or material.

\section{W}

wave A wave is a disturbance that propagates through space (vacuum or no medium), in a material or medium, or at the interface between two media. A wave travels and transfers energy without permanent displacement of particles in the medium: that is, there is no associated net mass transport; instead, particles oscillate about fixed positions. Waves are usually characterized by periodicity, meaning that maximum and minimum amplitudes or particle displacements occur repetitively in time or in space. 


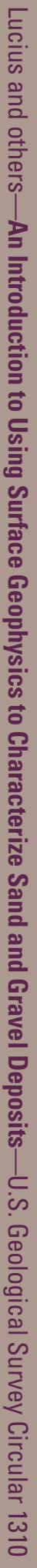

89 Printed on recycled paper 